\title{
The level of putative carotenoid-binding proteins determines the body color in two species of endemic Lake Baikal amphipods
}

Polina Drozdova ${ }^{\text {Corresp., }, 1,2}$ Alexandra Saranchina ${ }^{1}$, Mariya Morgunova ${ }^{1}$, Alena Kizenko ${ }^{3,4}$, Yulia Lubyaga ${ }^{1,2}$, Bois $^{2}$ Baduev $^{1}$, Maxim Timofeyev ${ }^{\text {Corresp. } 1,2}$

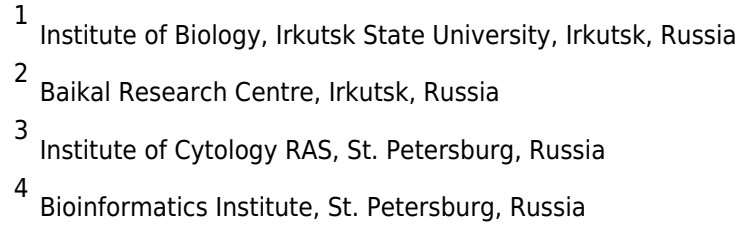

Color is an essential clue for intra- and interspecies communication, playing a role in selection and speciation. Coloration can be based on nanostructures and pigments; carotenoids and carotenoproteins are among the most widespread pigments in animals. Over 350 species and subspecies of amphipods (Crustacea: Amphipoda) endemic to Lake Baikal exhibit an impressive variability of colors and coloration patterns, including intraspecific color morphs. However, the mechanisms forming this diversity are underexplored, as while the carotenoid composition of several transparent, green, and red species was investigated, there have been no reports on the corresponding carotenoidbinding proteins. In this work, we analyze the coloration of two brightly colored Baikal amphipods characterized by intraspecific color variability, Eulimnogammarus cyaneus and E.vittatus. We showed that the color of either species is defined by the level of putative carotenoid-binding proteins similar to the pheromone/odorant-binding protein family, as the concentration of these putative crustacyanin analogs was higher in blue or teal-colored animals than in the orange- or yellow-colored ones. At the same time, the color did not depend on the total carotenoid content, as it was similar between animals of contrasting color morphs. By exploring the diversity of these sequences within a larger phylogeny of invertebrate crustacyanins, we show that amphipods lack orthologs of the well-studied crustacyanins $A$ and $C$, even though they possess some crustacyanin-like sequences. The analysis of expression levels in E. cyaneus showed that the transcripts encoding crustacyanin analogs had much higher expression than the crustacyanin-like sequences, suggesting that the former indeed contribute to the color of these brightly colored animals. The crustacyanin analogs seem to act in a similar way to the well-studied crustacyanins in bodv color formation, but the details of their action are still to be revealed. 


\section{The level of putative carotenoid-binding proteins determines \\ 2 the body color in two species of endemic Lake Baikal \\ 3 amphipods}

4

5 Polina Drozdova ${ }^{1,2}$, Alexandra Saranchina ${ }^{1}$, Mariya Morgunova ${ }^{1}$, Alena Kizenko ${ }^{3,4}$, Yulia

6 Lubyaga $^{1,2}$, Boris Baduev ${ }^{1}$ and Maxim Timofeyev ${ }^{1,2}$

$7 \quad{ }^{1}$ Institute of Biology, Irkutsk State University, Irkutsk, Russia

$8 \quad{ }^{2}$ Baikal Research Centre, Irkutsk, Russia

$9 \quad{ }^{3}$ Institute of Cytology RAS, St. Petersburg, Russia

$10 \quad{ }^{4}$ Bioinformatics Institute, St. Petersburg, Russia

11

12 Corresponding Authors:

13 Dr. Sci., Prof. Maxim Timofeyev ${ }^{1,2}$

14 Irkutsk State University,

15 3-117 Lenin str., 664025, Irkutsk, Russia

16 Email address: m.a.timofeyev@gmail.com

Dr. Polina Drozdova ${ }^{1,2}$

19 Irkutsk State University,

20 3-120 Lenin str., 664025, Irkutsk, Russia

21 Email address: drozdovapb@gmail.com 


\section{Abstract}

23 Color is an essential clue for intra- and interspecies communication, playing a role in selection

24 and speciation. Coloration can be based on nanostructures and pigments; carotenoids and 25 carotenoproteins are among the most widespread pigments in animals. Over 350 species and 26 subspecies of amphipods (Crustacea: Amphipoda) endemic to Lake Baikal exhibit an impressive variability of colors and coloration patterns, including intraspecific color morphs. However, the mechanisms forming this diversity are underexplored, as while the carotenoid composition of several transparent, green, and red species was investigated, there have been no reports on the corresponding carotenoid-binding proteins. In this work, we analyze the coloration of two brightly colored Baikal amphipods characterized by intraspecific color variability, Eulimnogammarus cyaneus and E. vittatus. We showed that the color of either species is defined by the level of putative carotenoid-binding proteins similar to the pheromone/odorant-binding protein family, as the concentration of these putative crustacyanin analogs was higher in blue or teal-colored animals than in the orange- or yellow-colored ones. At the same time, the color did not depend on the total carotenoid content, as it was similar between animals of contrasting color morphs. By exploring the diversity of these sequences within a larger phylogeny of invertebrate crustacyanins, we show that amphipods lack orthologs of the well-studied crustacyanins A and $\mathrm{C}$, even though they possess some crustacyanin-like sequences. The analysis of expression levels in E. cyaneus showed that the transcripts encoding crustacyanin analogs had much higher expression than the crustacyanin-like sequences, suggesting that the former indeed contribute to the color of these brightly colored animals. The crustacyanin analogs seem to act in a similar way to the well-studied crustacyanins in body color formation, but the details of their action are still to be revealed.

\section{Introduction}

6 Color is an important visual clue for many groups of organisms. The observed variety of colors 47 is based on two principles, which are structural coloration and pigments (Cuthill et al., 2017).

8 Carotenoids are one of the most widespread pigments in animal coloration, even though the 9 absolute majority of animal species cannot synthesize carotenoids de novo and thus rely on their 50 presence in the food source (Maoka, 2019). 
51 Lake Baikal is home to over 350 endemic species and subspecies of gammaridean 52 amphipods (Crustacea: Malacostraca: Amphipoda), which constitutes about half of the diversity 53 of the amphipod fauna of surface freshwaters (Takhteev, 2019). These species differ significantly

54 by preferred habitats and appearance. Different species are adapted to diverse conditions from 55 the water edge to the depths below $1500 \mathrm{~m}$ (Takhteev et al., 2015), but their morphological 56 diversity cannot be explained solely by adaption to habitat. One of the most evident aspects of 57 this diversity is the pronounced variability of body color and coloration pattern (Fig. 1). The 58 overall intensity of body color varies from almost transparent (e.g., Macrohectopus branickii 59 (Dybowsky, 1874)) or white species (e.g., Ommatogammarus albinus (Dybowsky, 1874)) to 60 blood red (Eulimnogammarus cruentus ((Dorogostaysky, 1930)), dark olive-green (e.g., E. 61 verrucosus (Gerstfeldt, 1858) or Pallasea cancellus (Pallas, 1776)), blue or orange (E. cyaneus 62 (Dybowsky, 1874)) or violet-blue (E. czerskii (Dybowsky, 1874)). For some species (including 63 mass littoral species E. vittatus (Dybowsky, 1874), E. cyaneus, and E. messerschmidtii Bedulina 64 et Takhteev 2014), subspecific color morphs are known (Timoshkin, 2001; Bedulina et al., 2014). 65 However, the molecular mechanisms underlying color formation in Baikal endemic amphipods 66 are underexplored. Only the carotenoid composition of several transparent, green, and red species was investigated (Czeczuga, 1975; Dembitsky and Rezanka, 1996), but these studies did not find a mechanism allowing for the formation of this coloration diversity.

The major player determining morphological body coloration in crustaceans are carotenoid pigments, especially astaxanthin and its derivatives. The level of carotenoids was shown to be correlated with the body color in several amphipod species of the genus Gammarus (Hindsbo, 1972; Gaillard et al., 2004), in which carotenoid depletion due to acanthocephalan infection leads to a change in color. However, the relationship between the total carotenoid content and body color is not as simple. In shrimps, carotenoid content may also be the reason behind the characteristic color of some morphs, as albino Fenneropenaeus merguiensis individuals had the lowest astaxanthin content (Ertl et al., 2013), but in other cases, the body color did not correlate with the total carotenoid content (Ertl et al., 2013; Tume et al., 2009).

Among the factors adding complexity to color determination are the distribution of carotenoids in the epithelial tissue (Wade et al., 2015), carotenoid composition and carotenoidbinding proteins. These proteins expand the palette of carotenoid-based colorations to cover the 
82 example of such proteins is the lobster (Homarus gammarus) shell protein, crustacyanin, which

83 binds to astaxanthin and provides the lobster carapace with its characteristic blue color

84 (Buchwald \& Jencks, 1968; Chayen et al., 2003). Crustacyanins, belonging to the lipocalin

85 family and found in decapods and stomatopods, appear to be a strictly crustacean-specific

86 innovation (Wade et al., 2009). Apart from lobster species, they were explored on the sequence

87 level in other decapods, mainly penaeid shrimps (Ertl et al., 2013; Budd et al., 2017). Decapod

88 crustacyanins form two groups, $\mathrm{A}$ and $\mathrm{C}$, which (at least in lobster) form heterodimers called $\beta$ -

89 crustacyanin binding to two astaxanthin molecules each, and eight $\beta$-crustacyanin subunits form

90 one $\alpha$-crustacyanin molecule (Chayen et al., 2003).

91 However, the structural and functional diversity of crustacyanins in amphipods remains

92 almost unknown: some crustacyanin-like sequences, forming a sister group to both A and C

93 groups of decapods, were found in expressed sequence tags of Gammarus pulex, but their

94 identity as crustacyanins remained unclear (Wade et al., 2009). In addition, two crustacyanin-like

95 proteins were isolated from G. lacustris with ion-exchange chromatography (Czeczuga \&

96 Krywuta, 1981), but the authors identified only the amino acid composition and not the

97 sequences of these proteins. So, while it is logical to suggest the existence of proteins acting as

98 crustacyanins in amphipods, their sequences and thus evolutionary origin remain unknown.

99 The goal of this work was to uncover the mechanism underlying the color formation in two

100 endemic Baikal amphipod species, E. cyaneus and E. vittatus. We estimated the carotenoid

101 content in individuals of different color morphs, characterized the putative carotenoid-binding

102 proteins analogous to crustacyanins, and placed them in the larger phylogeny of the invertebrate

103 coloration-related proteins.

\section{Materials and Methods}

105 Animals and sampling

106 Eulimnogammarus cyaneus (Dybowsky, 1874) is a relatively small (adult body size 11-15

$107 \mathrm{~mm}$ ) species widespread around the shoreline of Lake Baikal. It occupies the depths from the

108 water edge to several meters, concentrating near the shoreline (Bazikalova, 1945). The original

109 description of the species (as G. cyaneus) described its color as greyish blue (schmutzig blau)

110 (Dybowsky, 1874). The same epithet was reproduced when the species was reassigned to the 
111 genus Eulimnogammarus (Bazikalova, 1945). A newer source describes its color as "continuous

112 variation from sky blue to bluish-green, then with orange-red antennae, and to fully orange

113 individuals." This index also notes that the ratio of different color morphs varies along the coast,

114 but precopulae exist in all possible variations, and the prevailing morph was bluish-green with

115 orange antennae (Timoshkin, 2001). Our observations agree with these facts (Fig. S1). Moreover,

116 allozyme analysis showed that the orange and blue individuals appear to form panmictic

117 populations in all studied locations (Mashiko et al., 2000), again confirming the intraspecies

118 nature of this color polymorphism.

119 E. vittatus (Dyboswky, 1874) is a slightly bigger (adult body size 18-20 mm) species also 120 widespread in Lake Baikal littoral and found at up to 30-m depths, but concentrating mostly at 121 depth up to 2-3 m (Bazikalova, 1945). The original description of this species (as G. vittatus) 122 defined its color as light yellowish-green or light olive green with brownish stripes in the hind 123 part of each segment (Dybowsky, 1874). Newer sources (Timoshkin, 2001) note that the live 124 color of E. vittatus varies greatly as different shades of yellow, blue, and green, with the dark 125 stripes of the hind part of each segment being the common characteristic of all color morphs. 126 Most E. cyaneus individuals were sampled in August 2019 in Bolshie Koty (south-west 127 coast of Baikal; 51 $\left.54^{\prime} 11.67^{\prime \prime} \mathrm{N} 105^{\circ} 4^{\prime} 7.61^{\prime \prime} \mathrm{E}\right)$. Some photographs feature animals sampled near 128 Listvyanka $\left(51^{\circ} 52^{\prime} 14.07^{\prime \prime} \mathrm{N} 104^{\circ} 49^{\prime} 41.78^{\prime \prime} \mathrm{E}\right)$ in July 2019 . The individuals of E. vittatus were 129 sampled in Listvyanka in April 2019 and January 2020. The animals were caught with kick 130 sampling in Lake Baikal littoral at depths of 0-0.5 $\mathrm{m}$ and transported to the laboratory in 131 insulated boxes. In the laboratory, they were kept in 21 plastic tanks with Baikal water and 132 several sterilized Baikal stones per tank at $8 \pm 2{ }^{\circ} \mathrm{C}$ under constant aeration and fed ad libitum 133 with a dried and ground mixture of invertebrates and macrophytes from their habitat. The water 134 was exchanged once in three days. The blue and orange E. cyaneus individuals caught in August 135 were sorted immediately after sampling. All (103) orange individuals and approximately the 136 same number of blue ones (93 individuals) were kept in the same tank for three weeks to 137 normalize the environmental conditions before taking photographs and fixation.

\section{Photographs}

139 All photographs used for color quantification were taken with an Olympus Tough TG-5 camera

140 (Olympus, China) in the microscope mode against the same white background. One blue and one 
141 orange individual were included in each photograph to compensate for any unnoticed effects of 142 poor color balance. The photograph was loaded into the GIMP software (https://gimp.org), and 143 white balance was corrected against the white background with the Levels tool. Red, blue and 144 green color values were recorded with the Color Picker Tool in GIMP from the pereon (approx. $1456^{\text {th }}$ segment), gut (the best visible segment), pereopods, and antennae (whichever was the most 146 clearly visible). An example is shown in Fig. S2. The R/B ratio was subsequently used as a color 147 index, similarly to how it was applied to study color morphs of the coconut crab (Nokelainen et 148 al., 2017).

149 Some photographs were also taken with the Altami SPM0880 stereo microscope (Altami, 150 Russia) equipped with a camera (U3CMOS05100KPA, Altami, Russia); the white balance was 151 auto-corrected in the Altami Studio software prior to shooting against a 17\% grey paper.

\section{Animal fixation}

153 For most samples, the hemolymph was extracted with glass capillaries and immediately mixed 154 with anti-coagulation buffer (Shchapova et al., 2019) ( 1:1-1.5 volume/volume), appendages 155 were fixed in $96 \%$ ethanol, and the rest of the sample was shock frozen in liquid nitrogen.

\section{Carotenoid measurements}

157 Carotenoid concentration was assessed with a spectrophotometry-based method based on the 158 published procedures (British Standards Institute, 1977; Johnston et al., 2000; Razi Parjikolaei et 159 al., 2015) with modifications. Samples (either one whole E. vittatus individual or E. cyaneus individual devoid of hemolymph and several appendages, in both cases shock-frozen in liquid nitrogen and stored at $-80^{\circ} \mathrm{C}$ ) were put in the water near to the boiling temperature for $7-10$ seconds until the color changed to orange, dried with a paper towel and weighed. Then, carotenoids were extracted by homogenizing the samples in 1.5-3 $\mathrm{ml}$ acetone (Vekton, Russia) with stainless steel beads (Qiagen, Germany) using a Tissue lyser (Qiagen, Germany) in three consecutive rounds with default settings ( $50 \mathrm{rpm}$ for 2 minutes). Each time, the debris was pelleted, and the supernatant was collected into glass tubes. Then, the collected supernatant was mixed with 0.5-1 ml petroleum ether 40-70 (Ekos-1, Russia), and at least $10 \mathrm{ml}$ of distilled water was added to the mixture. After phase separation, the absorbance of the non-polar upper fraction was measured at the wavelengths from 200 to $800 \mathrm{~nm}$ with Cary $50 \mathrm{UV} / \mathrm{VIS}$ spectrophotometer 
170 (Varian Inc., Belrose, Australia). The purity of the extract was controlled by absorbance at 600 $171 \mathrm{~nm}$, and the concentration of carotenoids in parts per million (ppm) was estimated based on the 172 absorbance at $450 \mathrm{~nm}\left(\mathrm{~A}_{450}\right)$ as $4 \times \mathrm{A}_{450} \times \mathrm{V} / \mathrm{M}$, where $\mathrm{V}$ is the volume of petroleum ether used 173 for re-extraction (ml) and $\mathrm{M}$ is the wet sample weight (g) (British Standards Institute, 1977).

\section{Protein extraction and electrophoretic methods}

175 Hemolymph was used as the source for protein extraction, as it contained less distinct proteins

176

177

178

179

180

181

182

183

184

185

186

187

188

189

190

191

192

193

194

195

196

197

198

199

than the whole body extract, but as the color of the hemolymph generally matched the body color (see the Results section). For one-dimensional polyacrylamide gel electrophoresis (1D-PAGE), we added an equal amount of $2 x$ sampling buffer (Laemmli, 1970) to the hemolymph/anticoagulation buffer mixture (hemolymph of one animal was used), incubated it at $95{ }^{\circ} \mathrm{C}$ for 2 minutes, chilled on ice and loaded into $12 \%$ acrylamide gel blocks. The gels were run at $60 \mathrm{~V}$ for approximately $30 \mathrm{~min}$ and then at $120 \mathrm{~V}$ until the dye reached the end of the gel, according to the standard procedure (Sambrook et al., 1989). The PageRuler Prestained Protein Ladder, 10 to 180 $\mathrm{kDa}$ (Thermo Scientific, USA) was used to assess protein molecular weights.

Protein purification from hemolymph and two-dimensional PAGE (2D-PAGE) was performed according to the published method (Bedulina et al., 2016), except for the fact that cells were not pelleted, as they contribute only a small fraction of protein to the hemolymph. The hemolymph of ten E. cyaneus or four E. vittatus individuals was pooled in each sample.

Isoelectric focusing was run as described (Bedulina et al., 2016; Bedulina et al., 2017), and separation by molecular weight was also run according to this protocol, except for the fact that smaller gels were used in the case of E. cyaneus.

Native 2D-PAGE was run using essentially the same protocol, except for the fact that sodium dodecyl sulfate (SDS) and beta-mercaptoethanol were omitted from buffers, and the hemolymph was not heated before loading. After native electrophoresis, the bands of interest were cut out, incubated in loading buffer with SDS for at least $30 \mathrm{~min}$, loaded into the wells of a regular polyacrylamide gel and run under denaturing conditions.

All gels were stained with $0.2 \%$ Coomassie Brilliant Blue in $10 \%$ acetic acid / $25 \%$ ethanol and destained with hot distilled water. Gel densitometry was performed with the ImageJ/Fiji package (Schindelin et al., 2012; Schneider et al., 2012). The relative abundances of two putative crustacyanin spots were calculated as the ratios between the integrated optical density of the

Peer) reviewing PDF | (2020:01:44934:2:0:NEW 21 May 2020) 
200 corresponding spot to the sum of integrated optical density values for the two spots and the major 201 hemocyanin spot. The bands of interest were cut from gels with a scalpel in sterile conditions for 202 subsequent identification with liquid chromatography with tandem mass spectrometry (LC203 MS/MS).

204 205

206

207

208

209

210

211

212

213

214

215

216

217

218

219

220

221

222

223

224

225

226

227

228

\section{LC-MS/MS analysis}

Proteins were subjected to in-gel trypsin digestion according to the following procedure. After three washes in water, the gel pieces were incubated in $50 \%(\mathrm{v} / \mathrm{v})$ acetonitrile and $100 \mathrm{mM}$ ammonium bicarbonate ( $\mathrm{pH} \mathrm{8.9)}$ for $20 \mathrm{~min}$, then in $100 \%$ acetonitrile for $20 \mathrm{~min}$. The pieces were dried for $1 \mathrm{~h}$. Depending on the original size of the gel slice, 5-8 $\mu \mathrm{l}$ of trypsin solution (25 ng/ $\mu 1$ sequencing grade modified trypsin (Promega, Madison, WI, USA) in $50 \mathrm{mM}$ ammonium bicarbonate solution) were added, and protein hydrolysis was carried out at $37{ }^{\circ} \mathrm{C}$ overnight. Tryptic peptides were extracted by the addition of $15 \mu$ extraction solution (5\% acetonitrile, $0.5 \%$ formic acid) for $30 \mathrm{~min}$ and analyzed by LC-MS/MS.

The peptides were separated with high-performance liquid chromatography (Ultimate 3000 Nano LC System, Thermo Scientific, Rockwell, IL, USA) in a 15-cm long C18 column with an inner diameter of $75 \mu \mathrm{m}$ (Acclaim ${ }^{\circledR}$ PepMap ${ }^{\mathrm{TM}}$ RSLC, Thermo Fisher Scientific, Rockwell, IL, USA). The peptides were eluted with a gradient from $5-35 \%$ buffer B ( $80 \%$ acetonitrile, $0.1 \%$ formic acid) over $45 \mathrm{~min}$ at a flow rate of $0.3 \mu \mathrm{L} / \mathrm{min}$. Total run time including $5 \mathrm{~min}$ to reach $99 \%$ buffer B, flushing 5 min with $99 \%$ buffer B and 5 min re-equilibration to buffer $\mathrm{A}(0.1 \%$ formic acid) was $60 \mathrm{~min}$.

MS analysis was performed in triplicate with a Q Exactive HF mass spectrometer (Q Exactive $^{\mathrm{TM}}$ HF Hybrid Quadrupole-Orbitrap ${ }^{\mathrm{TM}}$ Mass spectrometer, Thermo Fisher Scientific, Rockwell, IL, USA). Mass spectra were acquired at a resolution of 120,000 (MS) and 15,000 (MS/MS) in an $m / z$ range of 350-1500 (MS) and 100-2000 (MS/MS). Isolation threshold of 100,000 counts was determined for precursor selection, and up to top 10 precursors were chosen for fragmentation with high-energy collisional dissociation (HCD) at $30 \mathrm{NCE}$ and $100 \mathrm{~ms}$ accumulation time. Precursors with a charged state of +1 were rejected, and all measured precursors were excluded from measurement for $20 \mathrm{~s}$. The mass spectrometry proteomics data have been deposited to the ProteomeXchange Consortium (Deutsch et al., 2020) via the PRIDE 
229 (Perez-Riverol et al., 2019) partner repository with the dataset identifier PXD018516 and 230 10.6019/PXD018516

231 Data analysis and bioinformatic methods

232 The comparison of relative protein abundances and carotenoid content was performed in the $\mathrm{R}$ 233 statistical environment (R Core Team, 2019) v3.6.1 and visualized with the ggplot2 package 234 (Wickham, 2016) v3.2.1 for R. Groups of samples were compared with the Mann-Whitney rank235 sum test with Holm correction for multiple comparisons where applicable.

236 The blastx command from the ncbi-blast+ package (Camacho et al., 2019) v2.2.28+ was 237 used to search for the sequences of H. gammarus crustacyanins A2 (P80007; Keen et al., 1991a) 238 and C1 (P80029; Keen et al., 1991b) in the published transcriptome assemblies of the studied 239 species (GEPS01 and GEPV01 from Naumenko et al., 2017; GHHW01 from Drozdova et al., 240 2019; NCBI IDs of the assemblies are shown here and elsewhere), as well as in the reassembled 241 data. Trinity (Grabherr et al., 2011) v2.8.5 was used to reassemble the E. vittatus transcriptome 242 from the published raw sequencing reads (Naumenko et al., 2017; SRA NCBI: SRR3467061). 243 The expression level of the transcripts was estimated with salmon (Patro et al., 2015) v0.12.0 244 with the wrapper script from Trinity v2.8.5. Protein sequences encoded by transcripts were 245 predicted with the getorf function of the emboss package (Hancock \& Bishop, 2004) v6.6.0.0. 246 The diamond package (Buchfink, Xie \& Huson, 2014) v0.9.23.124 was used to re-classify the 247 found sequences against the NCBI non-redundant protein database (Oct 10, 2017). The results 248 were visualized in the R statistical environment (R Core Team, 2019) with the ggplot2 package 249 (Wickham, 2016).

250

Protein sequence alignment was performed with prank (Löytynoja, 2013) v.170427. The 251 alignments were trimmed with trimal (Capella-Gutierrez, Silla-Martinez \& Gabaldon, 2009) 252 v1.4.rev22 and analyzed with iqtree (Nguyen et al., 2014) v1.6.12 to reconstruct the phylogeny; 253 model selection was performed automatically with ModelFinder (Kalyaanamoorthy et al., 2017), 254 and the topology was tested using 1,000 Shimodaira-Hasegawa approximate likelihood ratio test 255 (aLRT) bootstrap replicates and approximate Bayes (aBayes) tests (Guindon et al., 2010; 256 Anisimova et al., 2011). The physical properties of the proteins were predicted the SignalP-5.0 257 (Almagro Armenteros et al., 2019) (signal peptides) and ExPaSy (Gasteiger, 2003) (molecular 258 weight and isoelectric point) servers. 
Mass spectrometry data were searched with SearchGUI (Barsnes and Vaudel, 2018) v3.3.17.

260 Parameters were set as follows: tryptic specificity allowing two missed cleavage; precursor M/Z 261 tolerance of $10 \mathrm{ppm}$ and fragment $\mathrm{m} / \mathrm{z}$ tolerance of 0.5 Da tolerance for MS/MS ions; precursor 262 charge 2-4; carbamidomethylation of $\mathrm{C}$ as a fixed modification and oxidation of $\mathrm{M}$ as a variable 263 modification. The sequence databases contained the protein sequences predicted with 264 TransDecoder (Haas et al., 2013) v2.1.0 in the transcriptome assembly of the corresponding 265 species (GEPS01 and GEPV01; Naumenko et al., 2017), as well as common contaminants from 266 the cRAP database (https://www.thegpm.org/crap/). The SearchGUI output was analyzed and 267 visualized in PeptideShaker (Vaudel et al., 2015) v1.16.44. Peptide-spectrum matches, peptides 268 and proteins were validated at a 1.0\% false discovery rate estimated using the decoy hit 269 distribution (decoy sequences were added by PeptideShaker). Only proteins having at least two 270 unique peptides were considered as positively identified. Relative quantities of the proteins were 271 estimated with NSAF. The top protein hits were annotated with the NCBI blast web interfact. 272 The commands used for data analysis are listed in Text S1 for reproducibility and are also 273 available from GitHub (https://git.io/JfJMP).

\section{Results}

275 Field frequency and quantitative analysis of color morphs in E. cyaneus

276 To determine the proportion of differently colored individuals within the E. cyaneus population, 277 we sampled 3499 animals within 5 days and visually classified them as orange or blue. The final

278

279

280

281

282 283

284 285 286 287 number of orange animals was 104 , translating into a frequency of approximately $3 \%$. These animals and approximately the same number of blue (control) animals were kept in the same water tank to normalize for environmental conditions.

The animals were photographed to obtain a quantitative assessment of their color. We found individuals with different colors from completely blue to completely orange (Fig. 2A), and the RGB color values of the pereon suggested that the colors formed a continuous distribution rather than distinct clusters (Fig. 2B). The pereon R/B color index provided the largest median difference (over two-fold) between the morphs classified by eye (Fig. 2C). The color of the antennae did not differ between the orange and blue individuals (Fig. 2D). At the same time, the antennae color index correlated with the visible heterogeneity of the blue-colored individuals: 
288 while the pale blue animals had the lowest antennae R/B color index, the greenish animals of the 289 intermediate submorph had the highest index. As human-based classification turned out to be a 290 reliable proxy, we further compared typical blue- or orange-colored individuals.

\section{1}

292

293

294

295

296

297

298

299

300

301

302

303

304

305

306

307

308

309

310

311

312

313

314

315

316

\section{Total carotenoid content does not define the body color}

At the next step, we checked if the varying color intensity was determined by carotenoid content. Our previous observations showed that the color of animals upon ethanol fixation, which leads to protein denaturation, became the same (example in Fig. 3A), and the visible color intensity of ethanol extracts was also similar between the color morphs. To check this result quantitatively, we estimated the carotenoid content of six individuals from each end of the color distribution (as quantified using R/B pereon values; Fig. 3B). No significant difference in the overall carotenoid content of the body was found (Fig. 3C), indicating that other mechanisms were involved.

To additionally check our conclusions, we studied another Baikal endemic species belonging to the same genus, E. vittatus, which has a great variety of color morphs. In this case, we only studied the animals belonging to the most frequent yellow and teal morphs (examples shown in Fig. 3D). Again, the total carotenoid content was similar regardless of the color morph (Fig. 3E).

\section{The level of putative carotenoid-binding proteins correlates with the color morph}

However, the color of many crustaceans is determined by carotenoprotein complexes, mainly crustacyanins that extend the yellow-red palette of carotenoids by adding blue and violet hues (Maoka, 2011). These proteins have been explored in many decapod species, but there has been no information about the studied species and very scarce information for amphipods in general.

The hemolymph color, as judged by eye, matched the color group of the individual (Fig. $4 \mathrm{~A}-\mathrm{C}$, as well as $\mathrm{L}-\mathrm{N}$ ), but hemolymph protein extracts have much fewer protein spots (Bedulina et al., 2016). Thus, we decided to use hemolymph to look for potential differences in protein composition between differently colored animals. First, we checked that the hemolymph color correlated with the body color (Fig. 4D). Then, we extracted proteins from pooled hemolymph of ten blue or orange individuals of E. cyaneus or four teal or yellow individuals of E. vittatus and used the protein extract for 2D-PAGE (Fig. 4E-F and O-P, respectively; Fig. S3). We observed two major protein spots with molecular weights below $30 \mathrm{kDa}$ and acid isoelectric 
317 points that were present in all samples but were much more abundant (from two-fold to ten-fold 318 difference) in samples of blue or teal animals (Fig. 4E-F and O-P).

319 The absence of any other major spots of similar weight allowed us to use 1D-PAGE, which 320 requires less material, for quantification of these two proteins. Analysis of 12 E. cyaneus

321 individuals with 1D-PAGE showed that both bands were less abundant in the protein extracts 322 from the hemolymph of orange individuals that in those from the blue ones (Fig. 4G-I; Fig. S3) 323 with a three-fold change in median values and $\mathrm{p}<0.01$. Interestingly, the relative abundances of 324 the approximately $15-\mathrm{kDa}$ and the $25-\mathrm{kDa}$ bands were strongly correlated (Fig. S4A).

325 The putative carotenoid-binding protein bands were excised from gels and identified using 326 LC-MS/MS. Top protein hits (> 50 unique peptides matched; Table S3) were indeed proteins 327 with predicted low molecular weights, acid isoelectric points and signal peptides (Fig. 4J-K and 328 329 Q-R). To our surprise, the best blast hits for obtained sequences were unknown proteins from other crustacean species (Table S4), and no similar proteins from the Uniprot database were found. The only annotated protein hit with e-value $<10^{-20}$ was a predicted pheromone/general odorant-binding protein from an amphipod Trinorchestia longiramus (KAF2366110.1; Patra et al., 2020). It is important to note that different proteins of the pheromone/odorant-binding family bind a wide range of hydrophobic molecules and function beyond chemoreception (Pelosi et al., 2018). mechanism requires further investigation. So, the results of the biochemical analyses were overall similar for the two species, as the color morph strongly correlated with the amount of 
347 putative carotenoid-binding proteins. As these proteins are not very similar to classical

348 crustacyanins, we suggest calling them crustacyanin analogs.

349 Phylogenetic analysis suggests that the diversity of coloration-forming proteins in 350 Amphipoda formed independently from that in best-studied Decapoda

351 Finally, we placed the identified putative crustacyanin analogs within the broader picture of

352 known and putative invertebrate crustacyanins (Fig. 5). The known sequences included

353 crustacyanins A and C from penaeid shrimps (Fenneropenaeus merguiensis, Litopenaeus

354 vannamei and Penaeus monodon) (Budd et al., 2017) and the lobster H. gammarus (Keen et al.,

355 1991a; Keen et al., 1991b). To compare our results with the published phylogeny of

356 crustacyanins (Wade et al., 2009), we included the same sequences from G. pulex, as well as

357 putative carotenoid-binding proteins from blue copepods (Acartia fossae) and appendicularia

358 (Oikopleura dioica) (Mojib et al., 2014), and also searched the GenBank database for other

359 sequences annotated as crustacyanins. Among them, we found sequences from a brachyuran crab

360 Eriocheir sinensis and five sequences annotated as crustacyanins in the genome of a talitrid

361 amphipod Hyalella azteca (Poynton et al., 2018).

362 In addition, we wanted to know if the studied species possess proteins more similar to

363 decapod crustacyanins than the ones identified with mass spectrometry. To predict putative

364 crustacyanin sequences, we looked for sequences similar to H. gammarus crustacyanins A and C

365

366

367

368

369

370

371

372

373

374

375

376

in the published E. cyaneus assembly (GHHW01; Drozdova et al., 2019) and E. vittatus assembly (GEPV01; Naumenko et al., 2017). Then the protein sequences were predicted and reclassified against the non-redundant NCBI protein database. Six distinct sequences that had crustacyanins in the top ten hits were found only in the former. We supposed that, as the assemblies were filtered to remove contamination (Naumenko et al., 2017), some sequences may have failed to pass this filtering or expression level filtering, and thus we reassembled the transcriptome. In the new assembly, we found nine transcripts encoding three distinct putative crustacyanin-like proteins of E. vittatus.

The phylogenetic analysis (Fig. 5A) revealed that all of the sequences from Er. sinensis or amphipod species formed an outgroup for the A and $\mathrm{C}$ subunits in penaeid shrimps and lobsters. The same was true for the sequences from copepods and appendicularia, corroborating the original result (Mojib et al., 2014). The sequences revealed with the mass spectrometry analysis

Peer) reviewing PDF | (2020:01:44934:2:0:NEW 21 May 2020) 
377 clearly form an outgroup to all other sequences. We suggest that the putative crustacyanin

378

379

380

381

382

383

384

385

386

387

388

389

390

391

392

393

394

395

396

397

398

399

400

401

402

403

404

405

406

analogs also bind carotenoids producing blue-colored complexes, but formed independently of crustacyanins from another family of proteins binding hydrophobic molecules, odorant-binding proteins. Overall, these data may mean that proteins forming blue complexes with carotenoids emerged at least three times even within Crustacea and originated from at least two different protein families, lipocalins and odorant-binding proteins.

However, if the putative crustacyanin analogs, belonging to the odorant-binding family, are major proteins determining the color of the hemolymph, the function of crustacyanin-like sequences from these species remains even more elusive. It is worth noting that all the crustacyanin-like sequences had acid isoelectric points and predicted molecular weights below $30 \mathrm{kDa}$, corresponding quite well to the observed protein spots. Thus, we hypothesized that the spots could be mixtures of both classes of proteins. However, the crustacyanin-like proteins were not present, even in minor amounts, in mass spectrometry data. Another possibility could be that the crustacyanin analog proteins were restricted to hemolymph. To check for that, we compared the expression levels in 25 transcriptomic samples of E. cyaneus in control conditions published earlier (Drozdova et al., 2019). We found that the crustacyanin analogs had much higher expression levels that were at least two or three orders of magnitude higher than those of the crustacyanin-like transcripts (Fig. 5B). We suggest that the crustacyanin analogs play the main role in determining the body color, while the crustacyanin-like proteins play another role, which is still to be revealed.

\section{Discussion}

In this work, we studied the molecular basis of color formation in two species of endemic Lake Baikal amphipods, E. cyaneus and E. vittatus.

In these species, the carotenoid content was not the driving force of color distinction, as it was very similar between animals of contrasting color morphs (Fig. 3C and E). This distinguishes the mechanism of intraspecies color variability in Baikal endemic species from that in some other known examples. For example, blue individuals of G. lacustris, another gammaridean amphipod, differ from the usual greyish-brown ones by acanthocephalan infection and reduced carotenoid content caused by the infection (Hindsbo, 1972). Another example of color morphs differing by the level of carotenoids is penaeid shrimp Fenneropenaeus 
407 merguiensis (Ertl et al., 2013), but in this case, both crustacyanin and carotenoid levels, as well

408 as other factors, contributed to the formation of three morphs. Instead, we found that the

409 presence of contrasting color morphs is most probably linked to carotenoid-binding proteins (Fig.

410 4) but not to the total carotenoid content (Fig. 3).

411 For one of the species, E. cyaneus, we estimated the frequency of differently colored

412 animals. Orange-colored individuals of $E$. cyaneus were relatively rare $(\sim 3 \%)$ in our sample. Still,

413 there are important questions of how much this distribution may vary depending on the sampling

414 place and environmental conditions and how much the color may change throughout the life span

415 of an individual. We did not observe any noticeable changes in color while keeping animals for

416 several months fed ad libitum, as well as any striking difference in size or sex distribution of blue

417 and orange animals, but a deeper analysis is needed to draw informed conclusions. As differently

418 colored individuals coexist in the same microhabitats and most probably have access to the same

419 resources, the mechanism of this difference should have genetic control. It was earlier suggested

420 (Timoshkin, 2001) that color morphs in E. cyaneus exist as a two-allele system with

421 heterozygotes being the fittest. The genetic control of this trait might be even more complex to

422 form the observed continuous variability in E. cyaneus (Fig. 2) and the greater variability of

423 color morphs in E. vittatus (Fig. 1), and constitutes another interesting direction of further

424 research. These data also raise the question about the mechanism of color formation in another

425 Eulimnogammarus species with intraspecies color polymorphism, E. messerschmidtii, which is

426 quite similar to E. cyaneus and has a similar blue/orange color polymorphism, but in the former

427 species, the orange morph is more common (Bedulina et al., 2014).

428 While ecological aspects may contribute the frequency of differently colored individuals in

429 E. cyaneus, the observed intraspecific color variability correlates with the abundance of

430 particular protein spots (Fig. 4E-I), and, importantly, these proteins migrated in the colored

431 bands in native electrophoresis (Fig. S5). The same tendency was observed for E. vittatus (Fig.

$4324 \mathrm{O}-\mathrm{P}$ ). Identification of these proteins with mass spectrometry revealed that they did not belong

433 to the lipocalin family, similar to known crustacyanins; instead, they were similar to some

434 amphipod proteins annotated as belonging to the pheromone/odorant-binding proteins. These

435 proteins have a structure with a hydrophobic cavity and can bind a wide range of hydrophobic

436 molecules (Pelosi et al., 2016), so the idea that they might bind carotenoids is plausible. We 
437 hypothesize that these proteins play the role of amphipod crustacyanins and suggest calling the 438 proteins of this group crustacyanin analogs.

439 This finding leads to the question of whether amphipods possess homologs of decapod 440 crustacyanins. To answer this question, we searched the transcriptomes of the studied species for 441 sequences similar to lobster crustacyanins. These crustacyanin-like sequences, as well as five 442 sequences annotated as crustacyanins in the genome of $H$. azteca, an amphipod species 443 belonging to another suborder, and two expressed sequences from a more closely related 444 G. pulex formed a sister group to crustacyanins A and C. Interestingly, the crustacyanin-like 445 sequences from a brachyuran crab Er. sinensis also did not belong to the A or $\mathrm{C}$ subunit groups 446 (Fig. 5A). A similar analysis of blue-colored plankton species (a copepod Acartia fossae and an 447 appendicularian Oikopleura dioica) also revealed proteins of the lipocalin family forming an 448 outgroup to the A and C crustacyanin subunits (Mojib et al., 2014). As our analysis, similar to 449 the published ones, included sequences from full transcriptomes and a genome, it is unlikely that 450 451 some sequences more similar to A- or C-crustacyanins were missed in amphipods. We can safely assume that at least some species belonging to various groups of invertebrates (even decapods) exploit a similar mechanism to the lobster and shrimp but use some other proteins, and the 453 details of their action are a promising direction for future research.

The function of the crustacynin-like proteins in the studied amphipod species is so far unclear. Their predicted physical characteristics (molecular weight and isoelectric point) are very 456 similar to those of crustacyanin analogs, which we studied with mass spectrometry. As no trace of crustacyanin-like proteins was found in the mass spectrometry data, we conclude that they are absent at least from the hemolymph. To check if the crustacyanin analog proteins were specific to the hemolymph, we calculated their expression levels in published transcriptomic samples of E. cyaneus and found that the crustacyanin analogs had two or three orders of magnitude higher 462 expression than the crustacyanin-like sequences (Fig. 5A). Thus, we suppose that the crustacyanin-like proteins have a very specific function confined to particular organs or tissues, while the crustacyanin analogs sufficiently contribute to the visible body color. proteins act as octamers of heterodimers (Chayen et al., 2003), and the crustacyanins of penaeid shrimps probably act in a similar way, as they form two clear clusters on the phylogenetic tree (Budd et al., 2017). However, there is no available information on subunit composition except 
468 for the two distinct carotenoid-binding proteins forming blue complexes in G. lacustris

469 (Czeczuga \& Krywuta, 1981). In both studied species, we observed two groups of subunits 470 differing in molecular weight (Fig. 4E-G, and O-P), and the relative amount of both groups were 471 strongly correlated both on the protein (Fig. S4A) and transcript (Fig. S4B) levels. These data, 472 together with the presence of various bands forming a ladder on the second (denaturing) 473 direction of native 2D-PAGE (Fig. S5), hint at complex formation by these proteins, but this 474 hypothesis requires further investigation.

\section{Conclusions}

476 Here we characterized the coloration of two Baikal amphipod species with intraspecies color 477 morphs. We found that the coloration did not depend on the total carotenoid content, but 478 correlated with the level of putative carotenoid-binding proteins. These proteins, which we 479 suggest terming crustacyanin analogs, are not orthologous to the A and C crustacyanin subunits 480 of lobsters and shrimps, but are related to pheromone/odorant-binding proteins. We suggest that 481 crustacyanin analogs act similarly to the well-studied crustacyanins. However, the details of their 482 action, such as binding to particular carotenoids and the composition of complexes they may 483 form, are still to be revealed.

\section{Acknowledgments}

485 Mass spectrometric analysis was carried out using the equipment of the "Human Proteome" Core 486 Facility of the Institute of Biomedical Chemistry (Moscow, Russia). We are grateful to the staff 487 of the Facility and personally to Dr. Olga Tikhonova for their help. We would like to thank the 488 members of the "Biosystems' adaptation" lab, as well as to Polina Lipaeva and Timofey 489 Prodanov, for their help in sampling. We are grateful to Dr. Ekaterina Govorukhiva for her help 490 in species identification. Special thanks to Ekaterina Madyarova for laboratory assistance, 491 Ekaterina Shchapova for help with illustrations, Kseniya Vereshchagina for sharing photos of 492 amphipods, and Anton Gurkov for fruitful discussions. Last but not least, we would like to thank 493 the reviewers, Dr. Thomas Knigge and Dr. Nick Wade, for their help in improving the 494 manuscript. 


\section{References}

496 1. Almagro Armenteros JJ, Tsirigos KD, Sønderby CK, Petersen TN, Winther O, Brunak S, 497 von Heijne G, Nielsen H. 2019 SignalP 5.0 improves signal peptide predictions using deep 498 neural networks. Nat. Biotechnol. 37, 420-423. (doi:10.1038/s41587-019-0036-z)

499 2. Anisimova M, Gil M, Dufayard JF, Dessimoz C, Gascuel O. 2011 Survey of branch support 500 methods demonstrates accuracy, power, and robustness of fast likelihood-based

501

502 approximation schemes. Syst. Biol. 60, 685-99. (doi:10.1093/sysbio/syr041)

3. Barsnes H, Vaudel M. 2018 SearchGUI: A highly adaptable common interface for 503 proteomics search and de novo engines. Journal of proteome research, 17(7), 2552-2555.

504 (doi:10.1021/acs.jproteome.8b00175)

505

4. Bazikalova AY 1945. Amphipods of Lake Baikal. Proceedings of Baikal Limnological 506 Station 11, 1-440.

507

5. Bedulina D, Meyer MF, Gurkov A, Kondratjeva E, Baduev B, Gusdorf R, Timofeyev MA.

508

509

510

511

512

513

514

515

516

517

518

519

520

521

522

523

524

2017 Intersexual differences of heat shock response between two amphipods

(Eulimnogammarus verrucosus and Eulimnogammarus cyaneus) in Lake Baikal. PeerJ 5, e2864. (doi:10.7717/peerj.2864)

6. Bedulina DS, Gurkov AN, Baduev BK, Borvinskaya EV, Dimova MD, Timofeyev MA. 2016 Preliminary analysis of hemocyanins in hemolymph plasma of Baikal endemic amphipods. Journal of Stress Physiology \& Biochemistry. 12, 74-86.

7. Bedulina DS, Takhteev VV, Pogrebnyak SG, Govorukhina EB, Madyarova EV, Lubyaga YA, Vereshchagina KP, Timofeyev MA, Luckenbach T. 2014 On Eulimnogammarus messerschmidtii, sp. n. (Amphipoda: Gammaridea) from Lake Baikal, Siberia, with redescription of E. cyanoides (Sowinsky) and remarks on taxonomy of the genus Eulimnogammarus. Zootaxa 3838, 518. (doi:10.11646/zootaxa.3838.5.2)

8. British Standards Institute 1977 Method BS 684: section 2.20. London, British Standards Institute

9. Buchfink B, Xie C, Huson DH. 2014 Fast and sensitive protein alignment using DIAMOND. Nat. Meth. 12, 59-60. (doi:10.1038/nmeth.3176)

10. Buchwald M, Jencks WP. 1968 Properties of the crustacyanins and the yellow lobster shell pigment. Biochemistry 7, 844-859. (doi:10.1021/bi00842a043) 
525 11. Budd AM, Hinton TM, Tonks M, Cheers S, Wade NM. 2017 Rapid expansion of 526 pigmentation genes in penaeid shrimp with absolute preservation of function. J. Exp. Biol. 527

528

529

530

531

532

533

534

535

536

537

538

539

540

541

542

543

544

545

546

547

548

549

550

551

552

553

554

555 220, 4109-4118. (doi:10.1242/jeb.164988)

12. Camacho C, Coulouris G, Avagyan V, Ma N, Papadopoulos J, Bealer K, Madden TL. 2009 BLAST+: architecture and applications. BMC Bioinformatics 10, 421. (doi:10.1186/14712105-10-421)

13. Capella-Gutierrez S, Silla-Martinez JM, Gabaldon T. 2009 trimAl: a tool for automated alignment trimming in large-scale phylogenetic analyses. Bioinformatics 25, 1972-1973. (doi:10.1093/bioinformatics/btp348)

14. Chayen NE, Cianci M, Grossmann JG, Habash J, Helliwell JR, Nneji GA, Raftery J, Rizkallah PJ, Zagalsky PF 2003 Unravelling the structural chemistry of the colouration mechanism in lobster shell. Acta Crystallogr., Sect D 59, 2072-2082. (doi:10.1107/s0907444903025952)

15. Cuthill IC, Allen WL, Arbuckle K, Caspers B, Chaplin G, Hauber ME, Hill GE, Jablonski NG, Jiggins CD, Kelber A, Mappes J, Marshall J, Merrill R, Osorio D, Prum R, Roberts NW, Roulin A, Rowland HM, Sherratt TN, Skelhorn J, Speed MP, Stevens M, Stoddard MC, Stuart-Fox D, Talas L, Tibbetts E, Caro T. 2017 The biology of color. Science 357, eaan0221. (doi:10.1126/science.aan0221)

16. Czeczuga B. 1975 Carotenoids in thirteen species of Gammaridae from Lake Bajkał. Comp. Biochem. Physiol. B: Biochem. 50, 259-268. (doi:10.1016/0305-0491(75)90272-2)

17. Czeczuga B, Krywuta S. 1981 Investigations of carotenoprotein complexes in animals-III. Presence of crustacyanins in Gammarus lacustris G.O. Sars. Comp. Biochem. Physiol. B: Biochem. 70, 665-667. (doi:10.1016/0305-0491(81)90318-7)

18. Dembitsky VM, Rezanka T. 1996 Comparative study of the endemic freshwater fauna of Lake Baikal-VII. Carotenoid composition of the deep-water amphipod crustacean Acanthogammarus (Brachyuropus) grewingkii. Comp. Biochem. Physiol. B: Biochem. 114, 383-387. (doi:10.1016/0305-0491(96)00066-1)

19. Deutsch EW, Bandeira N, Sharma V, Perez-Riverol Y, Carver JJ, Kundu DJ, GarcíaSeisdedos D, Jarnuczak AF, Hewapathirana S, Pullman BS, Wertz J, Sun Z, Kawano S, Okuda S, Watanabe Y, Hermjakob H, MacLean B, MacCoss MJ, Zhu Y, Ishihama Y, Vizcaíno JA. 2020. The ProteomeXchange consortium in 2020: enabling 'big data' 
556

557

558

559

560

561

562

563

564

565

566

567

568

569

570

571

572

573

574

575

576

577

578

579

580

581

582

583

584

585

586

approaches in proteomics, Nucleic Acids Res, 48(D1), D1145-D1152. (doi:10.1093/nar/gkz984).

20. Drozdova P, Rivarola-Duarte L, Bedulina D, Axenov-Gribanov D, Schreiber S, Gurkov A, Shatilina Z, Vereshchagina K, Lubyaga Y, Madyarova E, Otto C, Jühling F, Busch W, Jakob L, Lucassen M, Sartoris FJ, Hackermüller J, Hoffmann S, Pörtner HO, Luckenbach T, Timofeyev M, Stadler PF. 2019 Comparison between transcriptomic responses to shortterm stress exposures of a common Holarctic and endemic Lake Baikal amphipods. BMC Genomics 20, 712 (doi:10.1186/s12864-019-6024-3)

21. Dybowsky BN 1874. Beitrage sür naheren Kenntnis der in dem Baikal-See vorkommenden niederen Krebse aus der Gruppe der Gammariden. Besobrasoff, Herausgegeben von der Russischen Entomologischen Gesellschaft zu St. Petersburg.

22. Ertl NG, Elizur A, Brooks P, Kuballa AV, Anderson TA, Knibb WR. 2013 Molecular characterisation of colour formation in the prawn Fenneropenaeus merguiensis. PLoS ONE 8, e56920. (doi:10.1371/journal.pone.0056920)

23. Gaillard M, Juillet C, Cézilly F, Perrot-Minnot M-J. 2004 Carotenoids of two freshwater amphipod species (Gammarus pulex and G. roeseli) and their common acanthocephalan parasite Polymorphus minutus. Comp. Biochem. Physiol. B: Biochem. 139, 129-136. (doi:10.1016/j.cbpc.2004.07.001)

24. Gasteiger E. 2003 ExPASy: the proteomics server for in-depth protein knowledge and analysis. Nucleic Acids Res. 31, 3784-3788. (doi:10.1093/nar/gkg563)

25. Grabherr MG, Haas BJ, Yassour M, Levin JZ, Thompson DA, Amit I, Adiconis X, Fan L, Raychowdhury R, Zeng Q, Chen Z, Mauceli E, Hacohen N, Gnirke A, Rhind N, di Palma F, Birren BW, Nusbaum C, Lindblad-Toh K, Friedman N, Regev A. 2011 Full-length transcriptome assembly from RNA-Seq data without a reference genome. Nat. Biotechnol. 29, 644-652. (doi:10.1038/nbt.1883)

26. Guindon S, Dufayard JF, Lefort V, Anisimova M, Hordijk W, Gascuel O 2010 New algorithms and methods to estimate maximum-likelihood phylogenies: assessing the performance of PhyML 3.0. Systematic biology, 59, 307-21. (doi.org/10.1093/sysbio/syq010)

27. Haas BJ, Papanicolaou A, Yassour M, Grabherr M, Blood PD, Bowden J, Couger MB, Eccles D, Li B, Lieber M, MacManes MD 2013. De novo transcript sequence reconstruction 
587

588

589

590

591

592

593

594

595

596

597

598

599

600

601

602

603

604

605

606

607

608

609

610

611

612

613

614

615

616

617

from RNA-seq using the Trinity platform for reference generation and analysis. Nat. Protoc. 8, 1494. (10.1038/nprot.2013.084)

28. Hancock JM, Bishop MJ. 2004 EMBOSS (The European Molecular Biology Open Software Suite). Dictionary of Bioinformatics and Computational Biology. (doi:10.1002/9780471650126.dob0206.pub2)

29. Hindsbo O. 1972 Effects of Polymorphus (Acanthocephala) on colour and behaviour of Gammarus lacustris. Nature 238, 333-333. (doi:10.1038/238333a0)

30. Johnston IA, Alderson R, Sandham C, Dingwall A, Mitchell D, Selkirk C, Nickell D, Baker R, Robertson B, Whyte D, Springate J. 2000 Muscle fibre density in relation to the colour and texture of smoked Atlantic salmon (Salmo salar L.). Aquaculture 189, 335-349. (doi:10.1016/s0044-8486(00)00373-2)

31. Kalyaanamoorthy S, Minh BQ, Wong TKF, von Haeseler A, Jermiin LS. 2017 ModelFinder: fast model selection for accurate phylogenetic estimates. Nat. Methods 14, 587-589. (doi:10.1038/nmeth.4285)

32. Keen JN, Caceres I, Eliopoulos EE, Zagalsky PF, Findlay JBC. 1991 Complete sequence and model for the A2 subunit of the carotenoid pigment complex, crustacyanin. Eur. J. Biochem. 197, 407-417. (doi:10.1111/j.1432-1033.1991.tb15925.x)

33. Keen JN, Caceres I, Eliopoulos EE, Zagalsky PF, Findlay JBC. 1991 Complete sequence and model for the $\mathrm{C} 1$ subunit of the carotenoprotein crustacyanin, and model for the dimer, beta-crustacyanin, formed from the $\mathrm{C} 1$ and A2 subunits with astaxanthin. Eur. J. Biochem. 202, 31-40. (doi:10.1111/j.1432-1033.1991.tb16340.x)

34. Laemmli UK. 1970 Cleavage of structural proteins during the assembly of the head of bacteriophage T4. Nature 227, 680-685. (doi:10.1038/227680a0)

35. Löytynoja A. 2013 Phylogeny-aware alignment with PRANK. In Methods in Molecular Biology, pp. 155-170. Humana Press. (doi:10.1007/978-1-62703-646-7_10)

36. Maoka T. 2011 Carotenoids in marine animals. Marine Drugs 9, 278-293. (doi:10.3390/md9020278)

37. Maoka T. 2019 Carotenoids as natural functional pigments. J. Nat. Med. (doi:10.1007/s11418-019-01364-x)

38. Mashiko K, Kamaltynov R, Morino H, Sherbakov DY. 2000 Genetic differentiation among gammarid (Eulimnogammarus cyaneus) populations in Lake Baikal, East Siberia. 
618

619

620

621

622

623

624

625

626

627

628

629

630

631

632

633

634

635

636

637

638

639

640

641

642

643

644

645

646

647

648

Fundamental and Applied Limnology 148, 249-261. (doi:10.1127/archiv-

$$
\text { hydrobiol/148/2000/249) }
$$

39. Mojib N, Amad M, Thimma M, Aldanondo N, Kumaran M, Irigoien X. 2014 Carotenoid metabolic profiling and transcriptome-genome mining reveal functional equivalence among blue-pigmented copepods and appendicularia. Molecular ecology 23, 2740-56. (doi:10.1111/mec.12781)

40. Naumenko SA, Logacheva MD, Popova NV, Klepikova AV, Penin AA, Bazykin GA, Etingova AE, Mugue NS, Kondrashov AS, Yampolsky LY. 2017 Transcriptome-based phylogeny of endemic Lake Baikal amphipod species flock: fast speciation accompanied by frequent episodes of positive selection. Mol. Ecol. 26, 536-553. (doi:10.1111/mec.13927)

41. Nguyen L-T, Schmidt HA, von Haeseler A, Minh BQ. 2014 IQ-TREE: A Fast and effective stochastic algorithm for estimating maximum-likelihood phylogenies. Molecular Biol. Evol. 32, 268-274. (doi:10.1093/molbev/msu300)

42. Nokelainen O, Stevens M, Caro T. 2017 Colour polymorphism in the coconut crab (Birgus latro). Evolutionary Ecology 32, 75-88. (doi:10.1007/s10682-017-9924-1)

43. Patra AK, Chung O, Yoo JY, Kim MS, Yoon MG, Choi JH, Yang Y 2020. First draft genome for the sand-hopper Trinorchestia longiramus. Scientific Data 7(1), 1-9. (doi:10.1038/s41597-020-0424-8)

44. Patro R, Duggal G, Love MI, Irizarry RA, Kingsford C 2017. Salmon provides fast and biasaware quantification of transcript expression. Nature methods 14(4), 417. (doi:10.1038/nmeth.4197)

45. Perez-Riverol Y, Csordas A, Bai J, Bernal-Llinares M, Hewapathirana S, Kundu DJ, Inuganti A, Griss J, Mayer G, Eisenacher M, Pérez E, Uszkoreit J, Pfeuffer J, Sachsenberg T, Yilmaz S, Tiwary S, Cox J, Audain E, Walzer M, Jarnuczak AF, Ternent T, Brazma A, Vizcaíno JA. 2019 The PRIDE database and related tools and resources in 2019: improving support for quantification data. Nucleic Acids Res, 47(D1), D442-D450 (doi:10.1093/nar/gky1106).

46. Poynton HC, Hasenbein S, Benoit JB, Sepulveda MS, Poelchau MF, Hughes DST, Murali SC, Chen S, Glastad KM, Goodisman MAD, Werren JH, Vineis JH, Bowen JL, Friedrich M, Jones J, Robertson HM, Feyereisen R, Mechler-Hickson A, Mathers N, Lee CE, Colbourne JK, Biales A, Johnston JS, Wellborn GA, Rosendale AJ, Cridge AG, Munoz-Torres MC, 
649

650

651

652

653

654

655

656

657

658

659

660

661

662

663

664

665

666

667

668

669

670

671

672

673

674

675

676

677

678

Bain PA, Manny AR, Major KM, Lambert FN, Vulpe CD, Tuck P, Blalock PJ, Lin YY, Smith ME, Ochoa-Acuña N, Chen MJM, Childers CP, Qu J, Dugan S, Lee LS, Chao H, Dinh H, Han Y, Doddapaneni HV, Worley KC, Muzny DM, Gibbs RA, Richards S. 2018 The toxicogenome of Hyalella azteca: a model for sediment ecotoxicology and evolutionary toxicology. Environmental Science \& Technology 52, 6009-6022. (doi:10.1021/acs.est.8b00837)

47. Razi Parjikolaei B, Bahij El-Houri R, Fretté XC, Christensen KV. 2015 Influence of green solvent extraction on carotenoid yield from shrimp (Pandalus borealis) processing waste. J. Food Eng. 155, 22-28. (doi:10.1016/j.jfoodeng.2015.01.009)

48. R Core Team (2019). R: A language and environment for statistical computing. $\mathrm{R}$ Foundation for Statistical Computing, Vienna, Austria. URL https://www.R-project.org/.

49. Sambrook J, Fritsch EF, Maniatis T. 1989 Molecular cloning: a laboratory manual. Cold Spring Harbor laboratory press.

50. Schindelin J,Arganda-Carreras I, Frise E, Kaynig V, Longair M, Pietzsch T, Preibisch S, Rueden C, Saalfeld S, Schmid B, Tinevez JY, White DJ, Hartenstein V, Eliceiri K, Tomancak P, Cardona A. 2012 Fiji: an open-source platform for biological-image analysis. Nature Methods 9, 676-682. (doi:10.1038/nmeth.2019)

51. Schneider CA, Rasband WS, Eliceiri KW. 2012 NIH Image to ImageJ: 25 years of image analysis. Nat. Methods 9, 671-675. (doi:10.1038/nmeth.2089)

52. Shchapova E, Nazarova A, Gurkov A, Borvinskaya E, Rzhechitskiy Y, Dmitriev I, Meglinski I, Timofeyev M. 2019 Application of PEG-Covered non-biodegradable polyelectrolyte microcapsules in the crustacean circulatory system on the example of the amphipod Eulimnogammarus verrucosus. Polymers 11, 1246. (doi:10.3390/polym11081246)

53. Takhteev VV, Berezina NA, Sidorov DA. 2015 Checklist of the Amphipoda (Crustacea) from continental waters of Russia, with data on alien species. Arthropoda Selecta. 24, 33570.

54. Takhteev VV. 2019 On the current state of taxonomy of the Baikal Lake amphipods (Crustacea: Amphipoda) and the typological ways of constructing their system. Arthropoda Selecta. 28, 374-402. 
679 55. Timoshkin OA 2001. Lake Baikal: diversity of fauna, problems of its immiscibility and 680 origin, ecology and "exotic" communities. Index of animal species inhabiting Lake Baikal 681 and its catchment area. Novosibirsk: Nauka.

682 56. Tume RK, Sikes AL, Tabrett S, Smith DM. 2009 Effect of background colour on the 683 distribution of astaxanthin in black tiger prawn (Penaeus monodon): Effective method for 684 improvement of cooked colour. Aquaculture 296, 129-135.

685 (doi:10.1016/j.aquaculture.2009.08.006)

686 57. Vaudel M, Burkhart JM, Zahedi RP, Oveland E, Berven FS, Sickmann A, Martens L, 687 Barsnes H 2015. PeptideShaker enables reanalysis of MS-derived proteomics data sets.

688 Nature biotechnology 33, 22-4. (10.1038/nbt.3109)

689 58. Wade NM, Tollenaere A, Hall MR, Degnan BM. 2009 Evolution of a novel carotenoid690 binding protein responsible for crustacean shell color. Mol. Biol. Evol. 26, 1851-1864. $691 \quad$ (doi:10.1093/molbev/msp092)

692 59. Wade NM, Budd A, Irvin S, Glencross BD. 2015 The combined effects of diet, environment 693 and genetics on pigmentation in the Giant Tiger Prawn, Penaeus monodon. Aquaculture 449, 694 78-86. (doi:10.1016/j.aquaculture.2015.01.023)

695 60. Wickham H. 2016 ggplot2: elegant graphics for data analysis. Springer. 


\section{Figure 1}

Representative photographs of some Lake Baikal endemic amphipod species.

(A) M. branickii (Dybowsky, 1874); (B) Brandtia latissima latior (Dybowsky, 1874); (C)

Micruropus wohlii wohlii (Dybowsky, 1874); (D) Gmelinoides fasciatus (Stebbing, 1899); (E) E. verrucosus (Gerstfeldt, 1858); (F-G) different color morphs of E. cyaneus (Dybowsky, 1874);

(H-J) different color morphs of E. vittatus (Dybowsky, 1874); (K) E. maackii (Gerstfeldt, 1858); (L-M) different color morphs of E. messerschmidtii (Bedulina et Takhteev, 2014); (N) E. ussolzewii ussolzewii (Dybowsky, 1874); (O) E. cruentus (Dorogostaisky, 1930); (P) O. albinus (Dybowsky, 1874); (Q) O. flavus (Dybowsky, 1874); (R) O. carneolus melanophthalmus Bazikalova, 1945. Photo credit (E, O): Kseniya Vereshchagina. 
The only pelagic species:

A Macrohectopus branickii (Dybowsky, 1874)

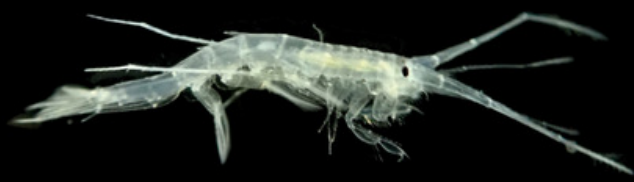

Littoral/sub-littoral benthic species:

B Brandtia latissima latior (Dybowsky, 1874)

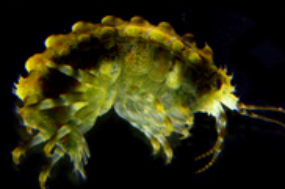

C

Micruropus wohlii wohlit

(Dybowsky, 1874)

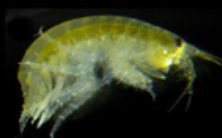

D Gmelinoides fasciatus (Stebbing, 1899)

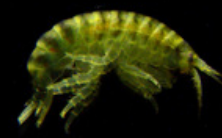

Eulimnogammarus verrucosus (Gerstfeldt, 1858)

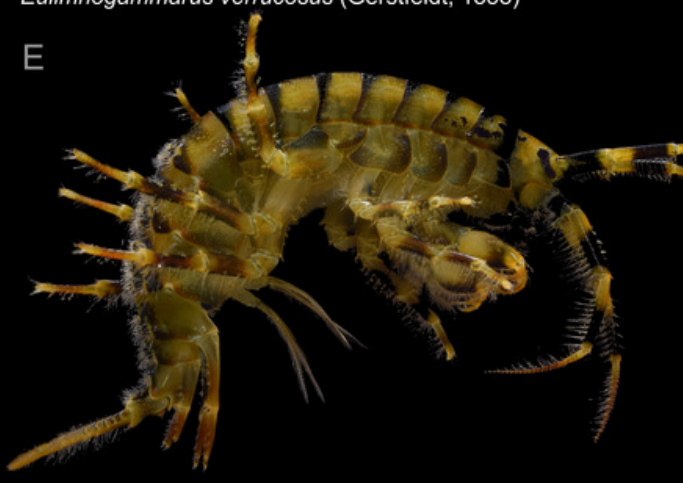

E

Eulimnogammarus maackii (Gerstfeldt, 1858)

K

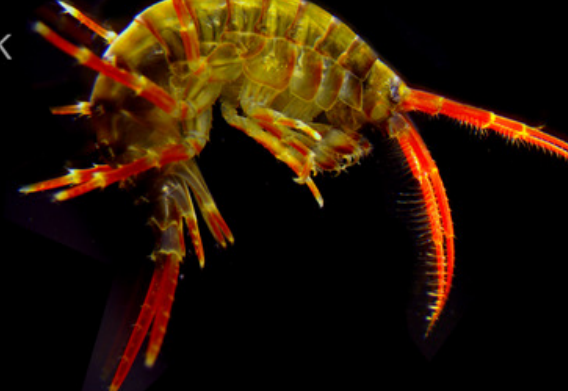

N
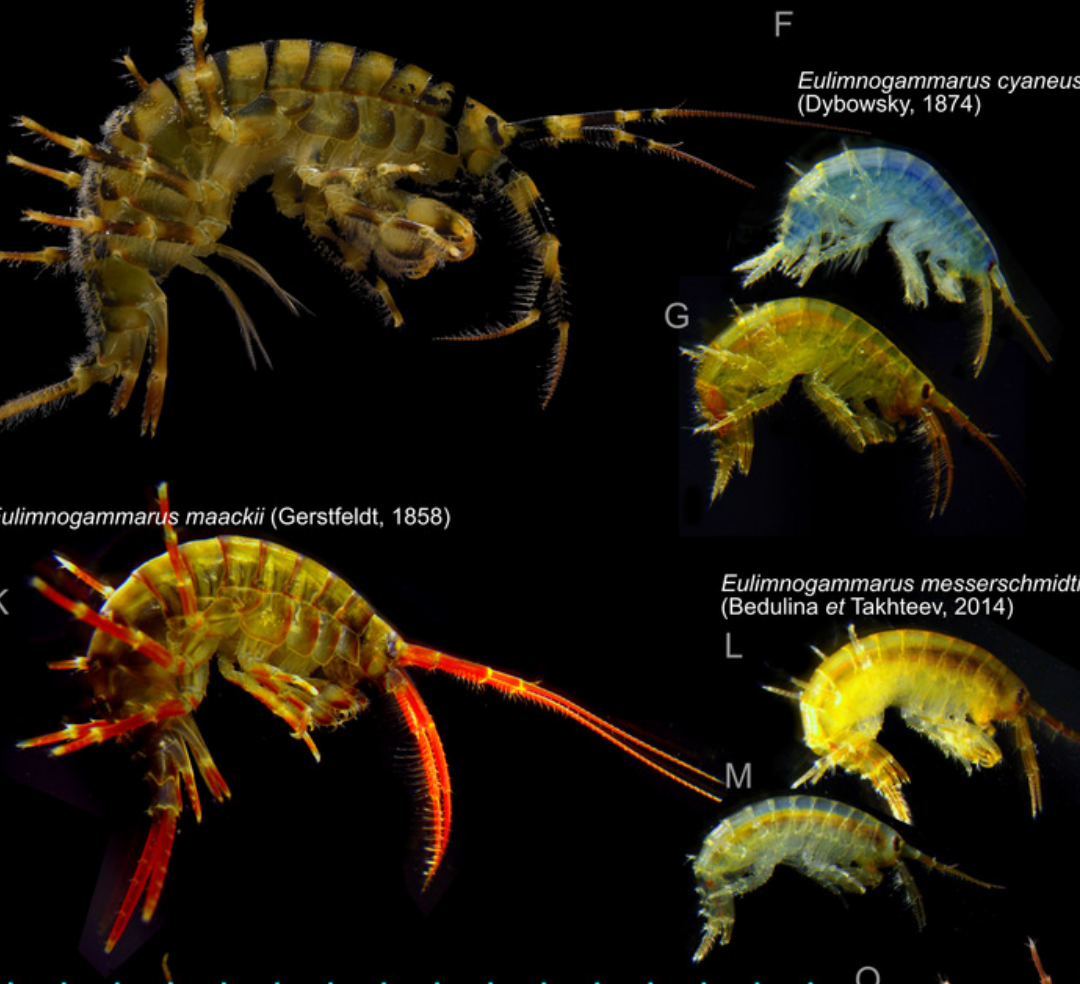

F

Eulimnogammarus vittatus (Dybowsky, 1874)
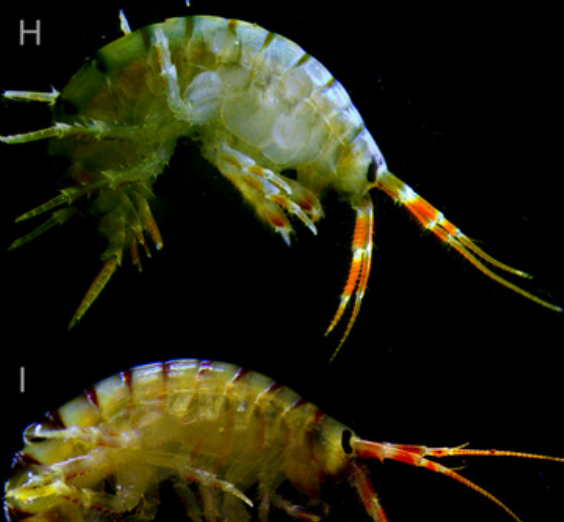

Eulimnogammarus messerschmidti (Bedulina et Takhteev, 2014)
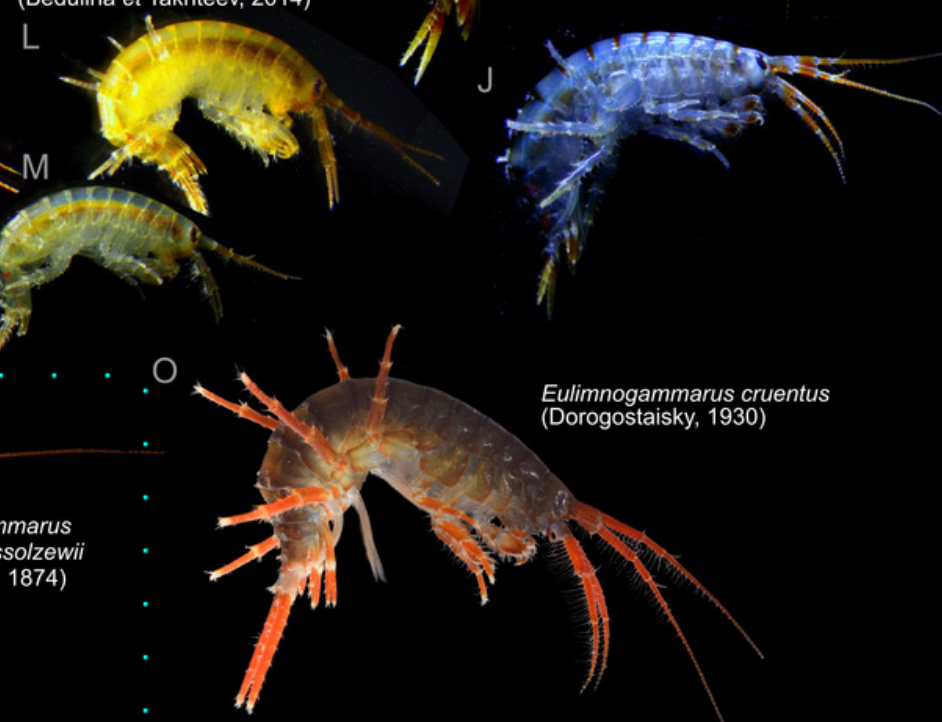

Eulimnogammarus cruentus (Dorogostaisky, 1930)

Eulimnogammarus ussolzewii ussolzewii

(Dybowsky, 1874)
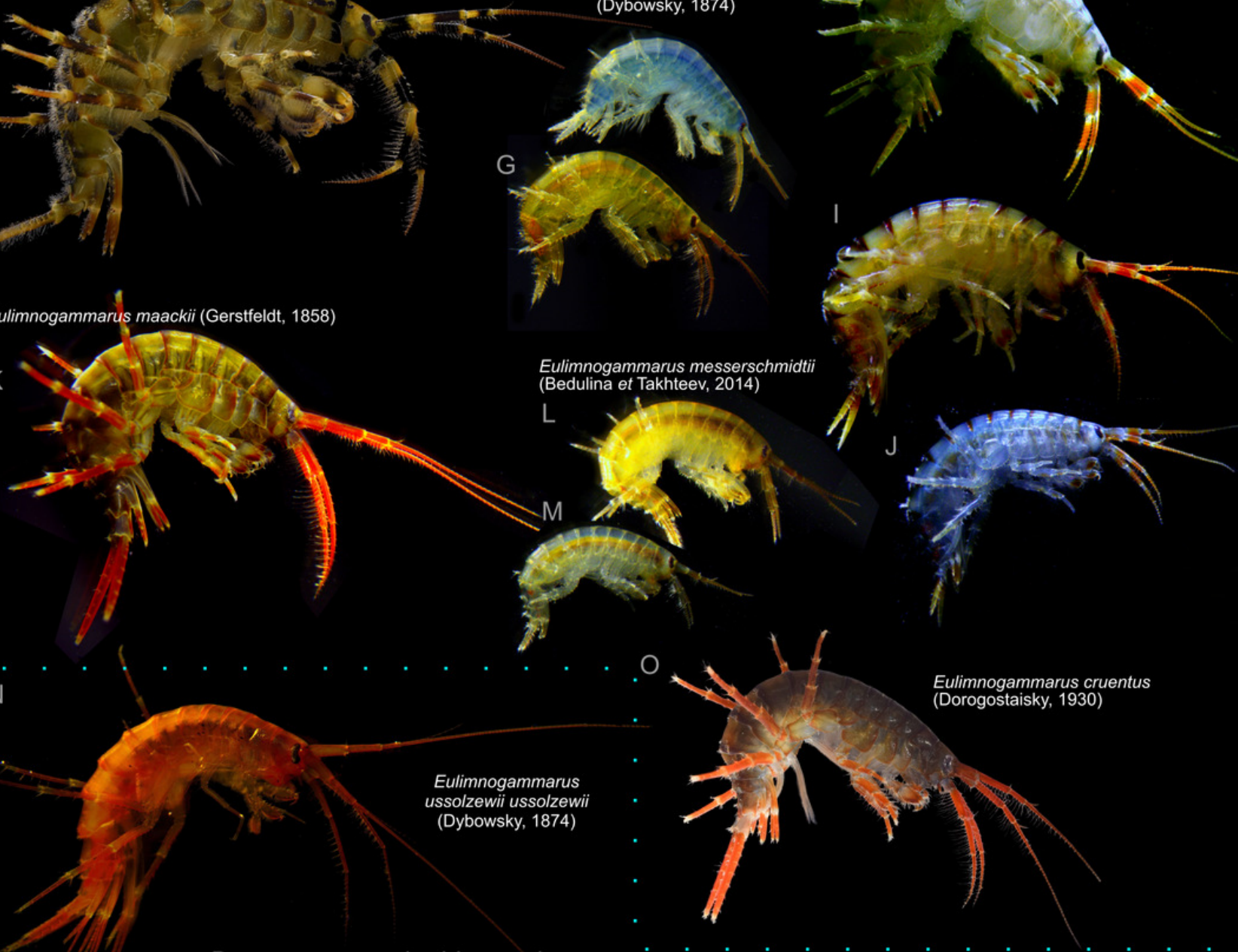

Deep-water eurybathic species:

Ommatogammarus albinus (Dybowsky, 1874)

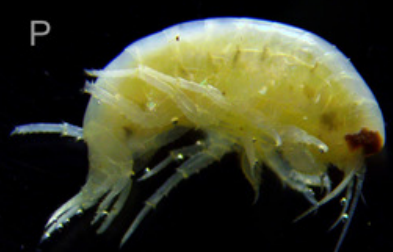

Ommatogammarus flavus (Dybowsky, 1874)

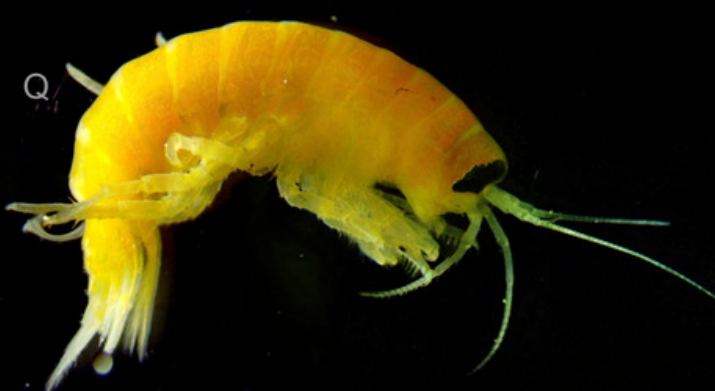

Ommatogammarus carneolus melanophthalmus Bazikalova, 1945

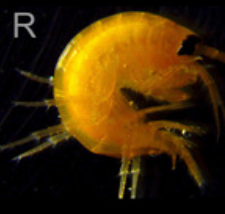




\section{Figure 2}

Quantitative analysis of $E$. cyaneus color morphs.

(A) Representative photographs of different morphs. (B) Principal component analysis results of pereon color. (C) Pereon color index in 76 individuals classified by eye into two groups. (D) Antennae color index in the same individuals. ${ }^{* *}, p<0.001$. Blue dots with cyan or green border mark pale blue individuals without orange tint and the intermediate ones between the blue- and orange-colored, respectively.

A

Morph:

Blue ( 97\%)

Submorph:

Pereon:

Antennae:

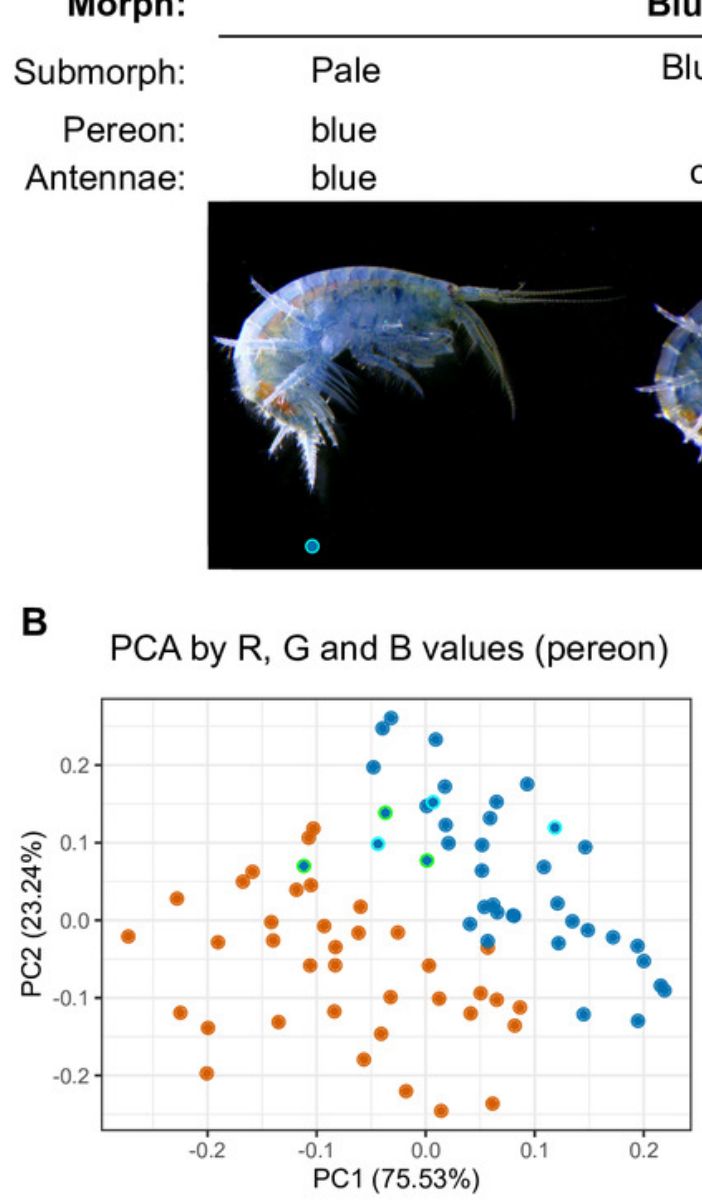

B

PCA by $R, G$ and $B$ values (pereon)

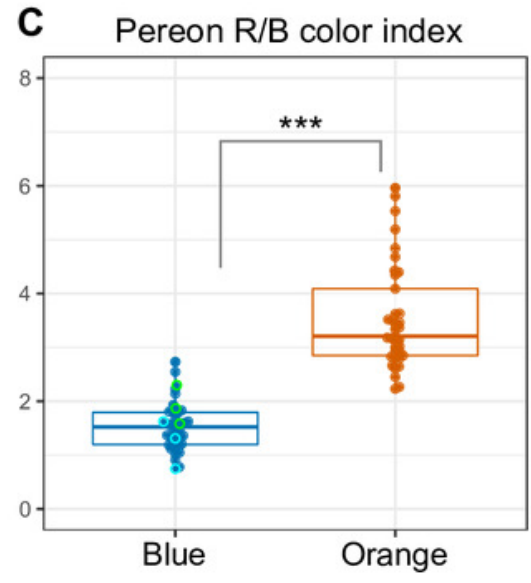

$\begin{array}{cc}\text { blue } & \text { blue / orange } \\ \text { range } & \text { orange }\end{array}$

Orange ( 3\%)

Intermediate

blue / orange

orange

orange

orange
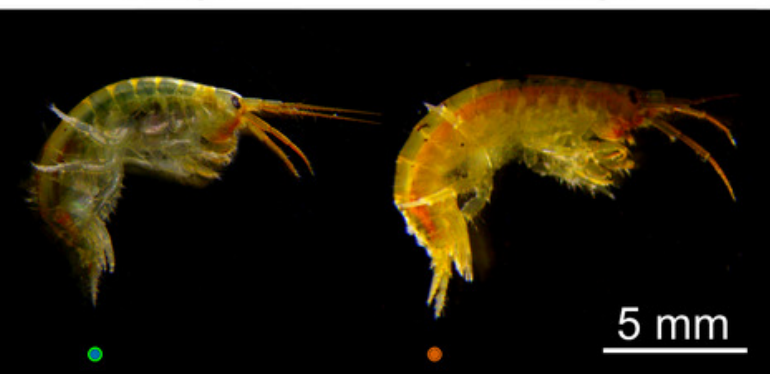

D Antennae R/B color index

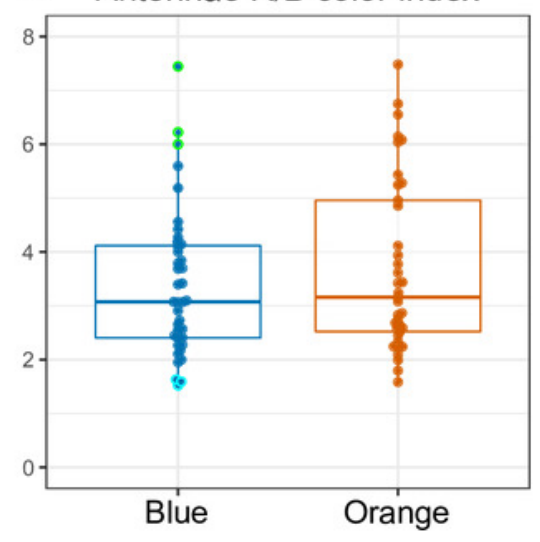




\section{Figure 3}

Carotenoid content does not define the color morph.

(A) Representative photographs of the same animals before and after ethanol fixation. (B)

Color index of the E. cyaneus individuals used for carotenoid extraction. This panel is based on the part of the data used for Fig. 2C. (C) Carotenoid content of the selected E. cyaneus samples. (D) A precopula of E. vittatus featuring a yellow male and a teal female. (E) Carotenoid content of three teal and five yellow animals.

A
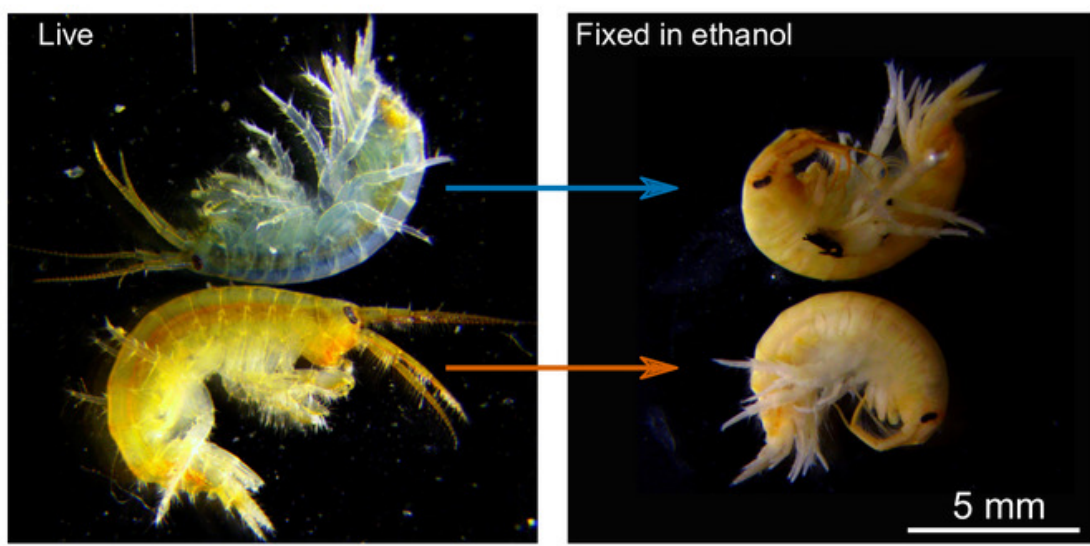

B Pereon R/B color index

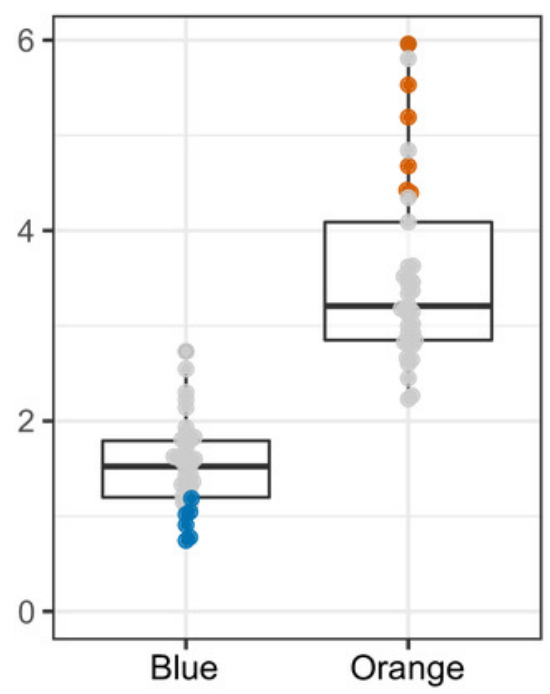

C

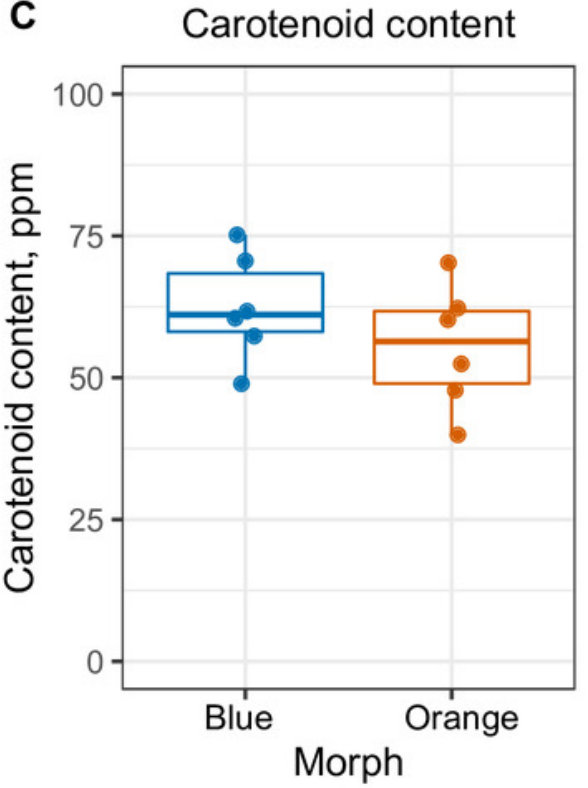

D

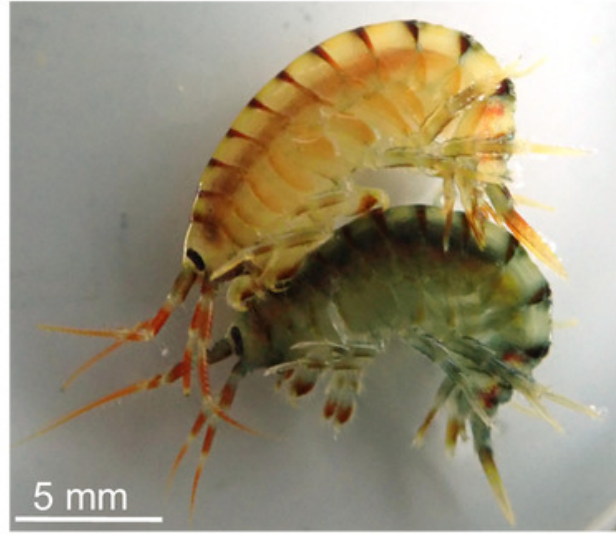

E Carotenoid content

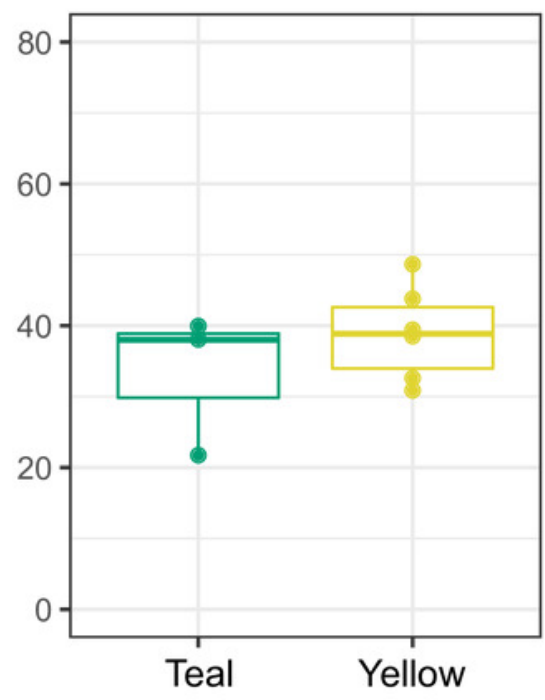




\section{Figure 4}

The hemolymph of blue $E$. cyaneus or teal $E$. vittatus possesses significantly higher amounts of putative crustacyanin analogs than the hemolymph of orange or yellow animals.

Panels A-K show the data for E. cyaneus, while panels L-R show the data for E. vittatus. (A and L) Representative photographs of animals of different color morphs. (B, C, M, and N) Representative photographs of the extracted hemolymph; in each case, the photograph is placed below the photograph of the animal of the same color morph. (D) Correlation between pereon and hemolymph color (quantified as the R/B value) of $15 E$. cyaneus individuals ( $E, F$, $O$, and P) Representative 2D-PAGE showing the difference in optical density of putative crustacyanin analogs. The hemolymph of ten individuals of $E$. cyaneus or four individuals of E. vittatus was pooled in each gel. Percent values correspond to the relative abundance of the protein spot. (G, H, and I) A representative 1D-PAGE and densitometry results for the 15$\mathrm{kDa}$ and 25-kDa putative crustacyanin analog bands, respectively, for 12 replicates for the bands in E. cyaneus. Uncropped gels are available in Fig. S3. ${ }^{*}, \mathrm{p}<0.01 .(\mathrm{J}, \mathrm{K}, \mathrm{Q}$, and R) Tandem mass spectrometry (MS/MS) peptide coverage of the 25-kDa and 15-kDa putative crustacyanin analogs for $E$. cyaneus and $E$. vittatus. 
A

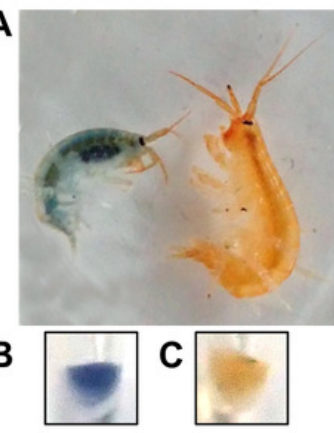

E Blue:

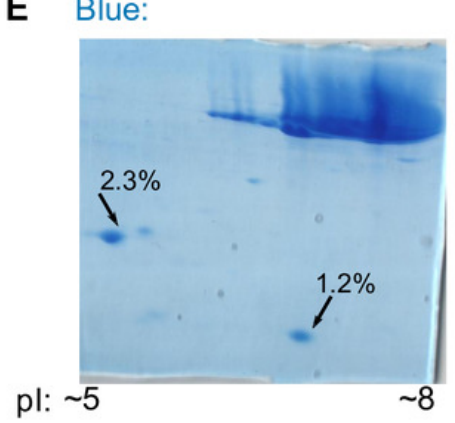

F Orange:

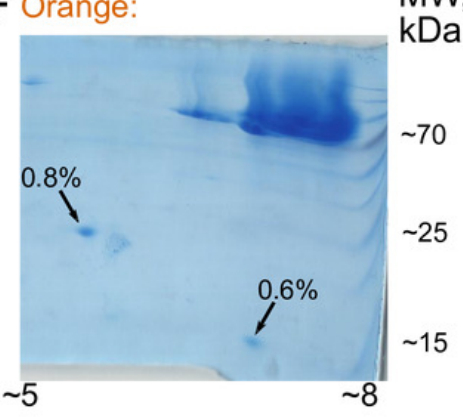

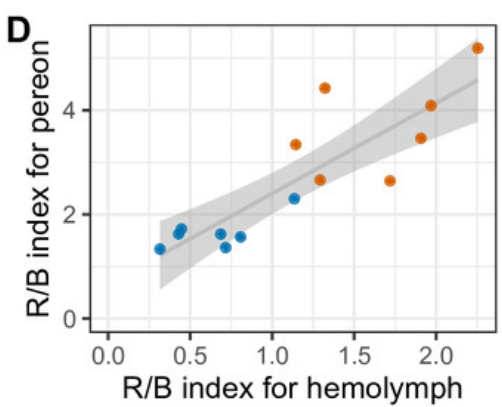

$\mathrm{R} / \mathrm{B}$ index for hemolymph
$\mathrm{Da}$

$-70$

5

$\sim 15$
$\mathbf{L}$

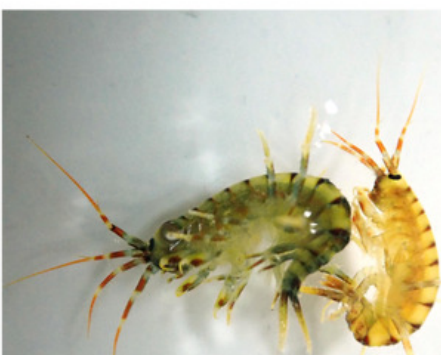

$\mathrm{MW}$

M
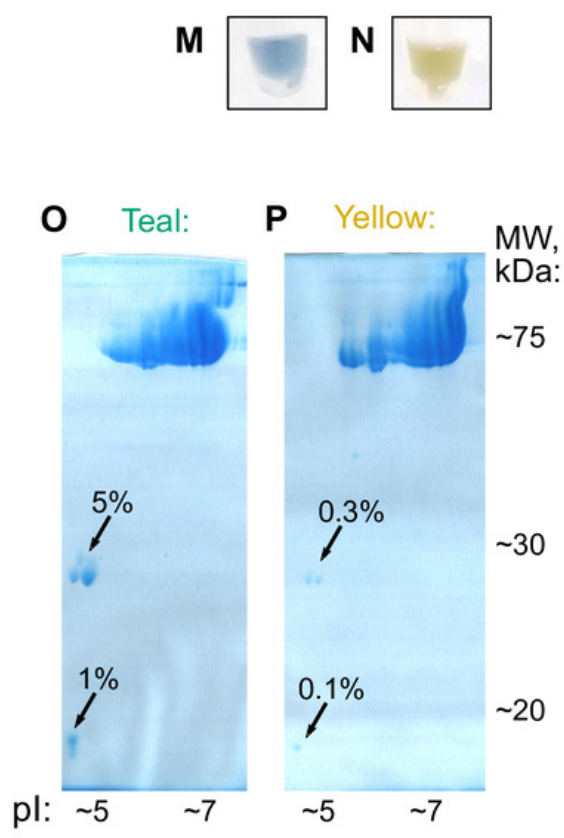

J

E. cyaneus, 25-kDa band:

GEPS01030296.1

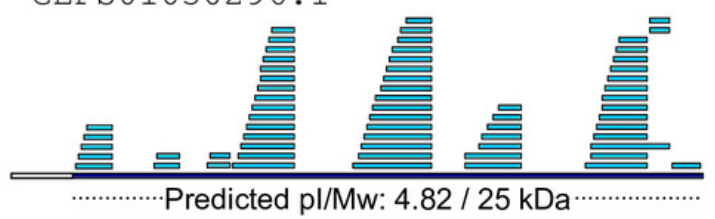

$\mathbf{K}_{\text {E. cyaneus, 15-kDa band: }}$

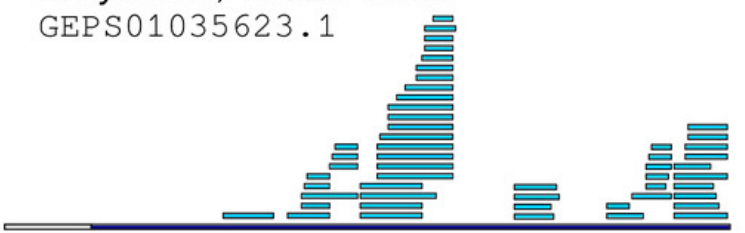

.......Predicted pl/Mw: $5.95 / 20$ kDa

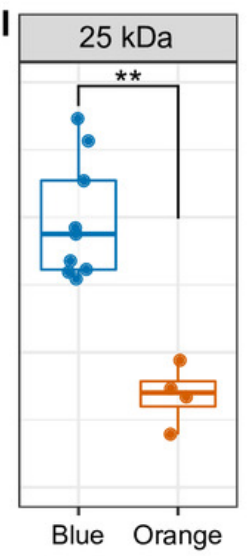

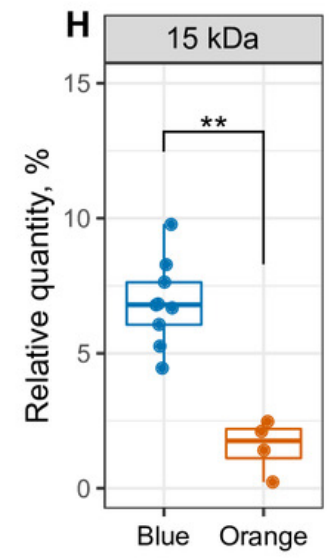

\section{Q}

E. vittatus, 25-kDa band: GEPV01033026.1

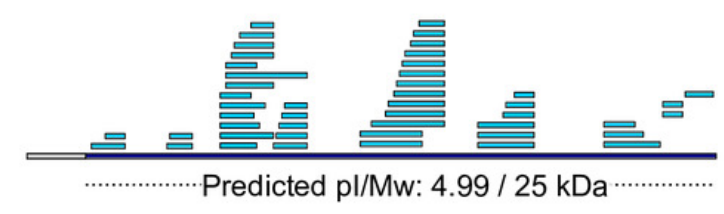

$\mathbf{R}$

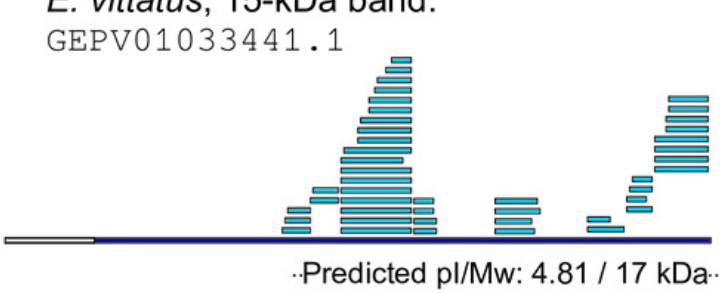




\section{Figure 5}

The diversity of predicted crustacyanin-like sequences in some amphipod species in comparison with those from different groups of decapods, as well as some copepods and appendicularia.

(A) A maximum-likelihood tree of predicted protein sequences. The shapes are added to visualize the taxa; the blue shapes mark proteins that are potentially coloration-related, while the gray shape marks an apolipoprotein D sequence not related to coloration. aLRT, Shimodaira-Hasegawa approximate likelihood ratio test; aBayes, approximate Bayes test. (B) Abundance of the transcripts encoding the putative crustacyanin analogs and crustacyaninlike proteins in E. cyaneus transcriptome samples. Each dot is one sample (pooled material of 5 animals). TPM, transcripts per million. 
A [GEPS01030296 Eülimnogammarus_cyaneus Putative crustacyanin analogs GEPV01033026 Eulimnogammarus_vittatus GEPS01035623 Eulimnogammarus_cyaneus
GEPV01033441 Eulimnogammarus_vittatus<smiles>Cc1ccccc1</smiles>

aLRT $>70 \%$ \&

aBayes posterior $>0.7$ GHHW01011113 Eulimnogammarus_cyaneus

LXP 018012730_CRCN-C1-like_Hyalella_azteca GHHW01018656 Eulimnogammarus_cyaneus _XP 018011458_CRCN-A2-like_Hyalella_azteca XP 018027662 _CRCN-A2-like__Hyalella_azteca TRINITY DN24_c0_g1_i9_1_Eulimnogammarus_vittatus GHHW01017383 Eulimnogammarus_cyaneus EH269222 Gammarus_pulex tEH270832 Gammarus_pulex

B

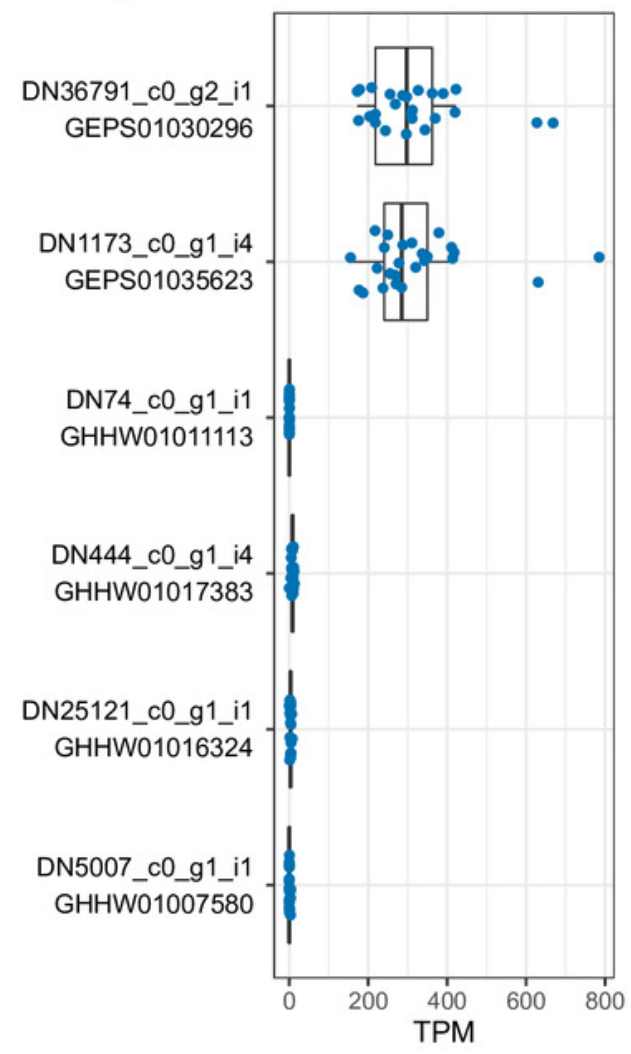

GHHW01016324 Eulimnogammarus_cyaneus

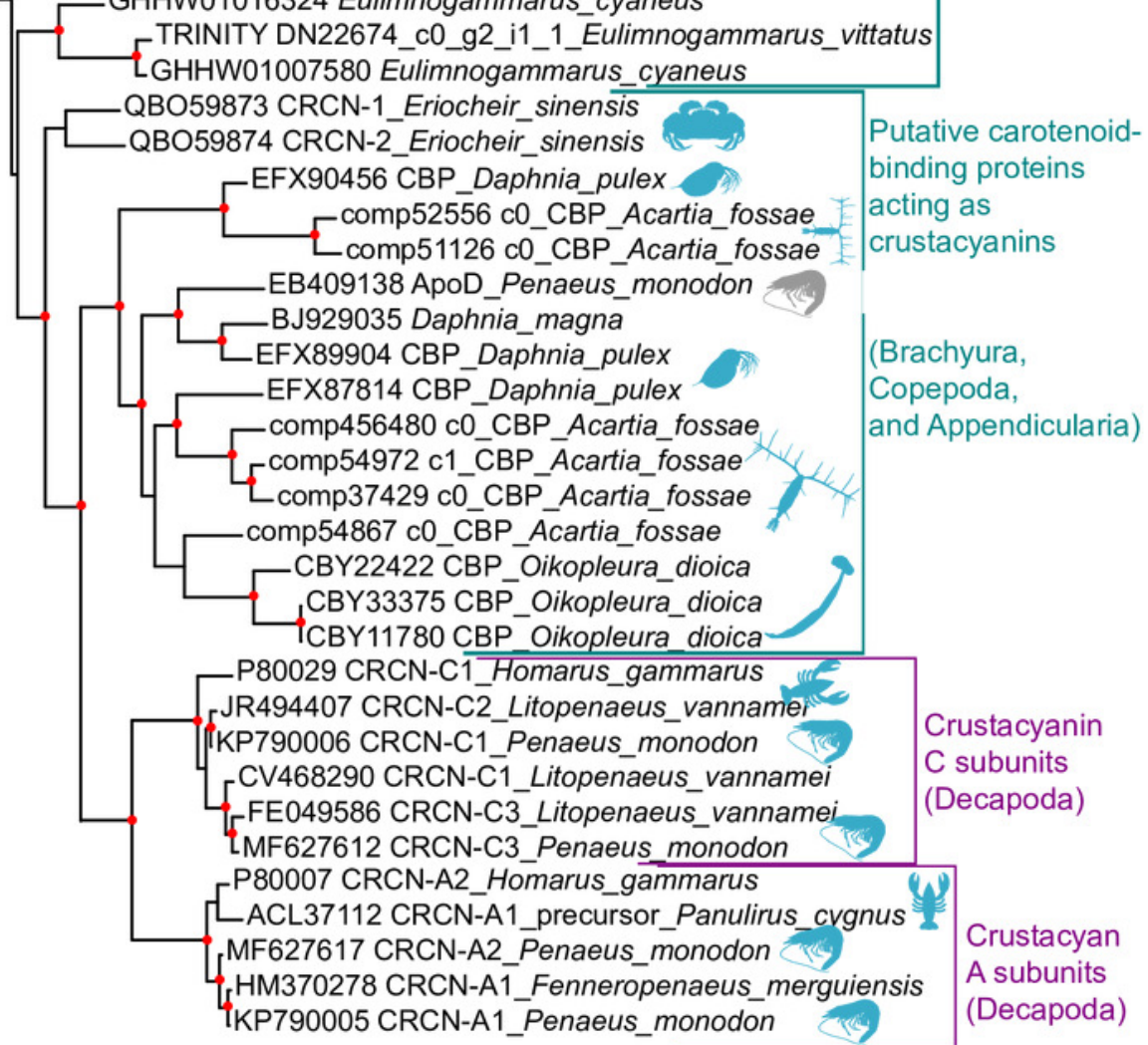

1

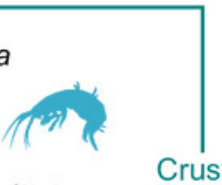

Crustacyanin-like sequences (Amphipoda)
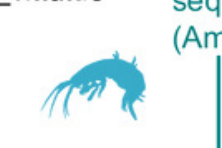